\title{
Systematic review regarding metabolic profiling for improved pathophysiological understanding of disease and outcome prediction in respiratory infections
}

Manuela Nickler ${ }^{1 \dagger}$, Manuel Ottiger ${ }^{1 \dagger}$, Christian Steuer ${ }^{2}$, Andreas Huber ${ }^{2}$, Janet Byron Anderson ${ }^{3}$, Beat Müller ${ }^{1}$ and Philipp Schuetz ${ }^{1,4^{*}}$

\begin{abstract}
Metabolic profiling through targeted quantification of a predefined subset of metabolites, performed by mass spectrometric analytical techniques, allows detailed investigation of biological pathways and thus may provide information about the interaction of different organic systems, ultimately improving understanding of disease risk and prognosis in a variety of diseases. Early risk assessment, in turn, may improve patient management in regard to cite-of-care decisions and treatment modalities. Within this review, we focus on the potential of metabolic profiling to improve our pathophysiological understanding of disease and management of patients. We focus thereby on lower respiratory tract infections (LRTI) including community-acquired pneumonia (CAP) and chronic obstructive pulmonary disease (COPD), an important disease responsible for high mortality, morbidity and costs worldwide. Observational data from numerous clinical and experimental studies have provided convincing data linking metabolic blood biomarkers such as lactate, glucose or cortisol to patient outcomes. Also, identified through metabolomic studies, novel innovative metabolic markers such as steroid hormones, biogenic amines, members of the oxidative status, sphingo- and glycerophospholipids, and trimethylamine-N-oxide (TMAO) have shown promising results. Since many uncertainties remain in predicting mortality in these patients, further prospective and retrospective observational studies are needed to uncover metabolic pathways responsible for mortality associated with LRTI. Improved understanding of outcome-specific metabolite signatures in LRTIs may optimize patient management strategies, provide potential new targets for future individual therapy, and thereby improve patients' chances for survival.
\end{abstract}

Keywords: Lower respiratory tract infection, Pneumonia, Chronic obstructive pulmonary disease, Mortality prediction, Steroid hormones, Biogenic amines, Trimethylamine-N-oxide, Intermediates energy metabolism, Monosaccharides, Oxidative status, Glycerophospholipids, Sphingolipids, Acylcarnitines

\section{Introduction}

\section{Metabolomics}

The metabolome can be considered the "quantitative complement of all the low molecular weight molecules $(<1500 \mathrm{amu})$ in a particular physiological or developmental state" of a cell, tissue or organism [1]. Metabolomics is

\footnotetext{
* Correspondence: schuetzph@gmail.com

${ }^{\dagger}$ Equal contributors

${ }^{1}$ Medical University Department, Division of General Internal and Emergency

Medicine, Kantonsspital Aarau, Aarau, Switzerland

${ }^{4}$ University Department of Medicine, Kantonsspital Aarau, Tellstrasse, CH-5001

Aarau, Switzerland

Full list of author information is available at the end of the article
}

defined as "the analysis of the whole metabolome under a given set of physiological, environmental and/or clinical conditions" [2]. Metabolite profiling through targeted quantification of a predefined subset of metabolites of the metabolome [3] allows analysis of metabolic pathways, thereby clarifying the interaction of different organic systems. While proteomics is the study of proteins made by the organism and the conditions under which the organism makes them, metabolomics is a more systematic study of the biochemical fingerprints that result of cellular processes. 
Mass spectrometry (MS) is a sensitive tool that characterizes and quantifies metabolites in a biological sample [4]. Since metabolomics requires proper separation of the different compounds to be analyzed, chemical separation techniques such as gas chromatography (GC) and liquid chromatography (LC) or capillary electrophoresis (CE) can be combined with MS detection. Analytical techniques such as LC-MS, GC-MS, CE-MS, and matrixassisted laser desorption ionization-MS (MALDI-MS) may therefore expand coverage of the metabolome [5]. MS is now a routine diagnostic instrument in clinical laboratories [6].

Biological information derived from these techniques can provide accurate and clinically useful diagnostic capability for the management of diseases $[7,8]$ by mapping disease risk to metabolic pathways [9]. Previously, many studies have focused on risk prediction in patients with lower respiratory tract infections (LRTI) including community-acquired pneumonia (CAP) and case (COPD) because such information may have direct consequences in patient management [10-13]. Early risk prediction may improve site-of-care decisions (i.e., ICU treatment vs. hospital ward vs. outpatient) as well as treatment modalities (i.e., antibiotic drugs) [11, 14, 15]. Indeed, improved understanding of metabolic interactions in LRTI patients may enhance prediction of outcomes and provide targets for individual therapy, which in turn could facilitate personalized patient management (Fig. 2) [16-18].

\section{Prediction of mortality in community-acquired pneumonia}

CAP is the leading cause of infectious death [19], and of high mortality, morbidity, and costs worldwide [20-22]. Patients with CAP manifest high short-term mortality $[23,24]$ but also substantial long-term morbiditiy [25-28]. To predict all-cause mortality within 30 days, the pneumonia severity index (PSI) is a validated tool that categorizes CAP patients within distinct risk classes (I-V) [29]. In Europe, the CURB-65 score (Confusion, Urea, Respiratory rate, Blood pressure, Age $>65$ years) is used for the same purpose [30]. Several clinical studies show that measuring specific inflammatory or metabolic blood biomarkers, including among others proadrenomedullin (proADM) $[14,15,31-33]$ and procalcitonin (PCT) $[26,34-36]$, provides prognostic information and possibly improves short-term risk stratification and management decisions in CAP compared to the use of clinical risk scores alone [37]. Pneumonia not only increases short-term mortality; clinical trials also found greater long-term mortality rates in patients who survived an initial CAP episode, compared to the general population and to patients who have other infections $[28,38,39]$. These observations suggest that CAP is a poor prognostic indicator of long-term outcomes.
Particularly, it has been hypothesized that cardiovascular events that are triggered by an episode of respiratory infection may be responsible for the excess mortality observed in large long-term CAP cohorts. For this reason, cardiovascular biomarkers (such as natriuretic peptides) may also help in the identification of high risk LRTI patients who need close monitoring and follow-up [28]. The metabolomics approach for LRTI thus may also look into metabolites that have been linked to cardiovascular disease as these conditions are being linked very closely.

\section{Prediction of mortality in patients hospitalized with exacerbated chronic obstructive pulmonary disease}

Prediction of outcomes in chronic obstructive pulmonary disease (COPD) is challenging. Three published observational studies suggest that the inflammatory blood biomarker ProADM independently predicts mediumterm all-cause mortality in patients with stable [40, 41] or exacerbated COPD. Additionally, measurement of ProADM combined with the clinical parameters of body mass index, airflow obstruction, dyspnea and exercise capacity index (BODE) [42] improves the predictive power of medium-term all-cause mortality compared to the use of BODE alone [40]. A recent observational clinical cohort study demonstrated that ProADM levels are independent predictors of 5- to 7-year all-cause mortality, and may enhance long-term prognostic accuracy of demographic and clinical variables in patients hospitalized for exacerbation of pneumonic or non-pneumonic COPD [32]. Similar to CAP, in COPD cardiovascular disease may be responsible for large portions of the high mortality associated with this disease. Again, the metabolomic approach in COPD may therefore also consider interesting metabolites associated with adverse cardiovascular outcomes.

\section{Aims of the review and methodology}

The goal of the present review is to investigate wether new metabolic blood biomarkers help optimizing identification of patients at risk for poor outcome in CAP and exacerbated COPD. We discuss nine metabolite classes: steroid hormones, biogenic amines, intermediate energy metabolism, monosaccharides, trimethylamines, oxidative status, sphingolipids, glycerophospholipids, and acylcarnitines. Each section will begin with a brief description of pathways and known physiological effects, followed by a summary of observational data regarding the analyte's role in predicting all-cause mortality. We focus on patients with LRTI which is responsible for high mortality, morbidity and costs worldwide. Yet, if no data are available in strictly LRTI patients, we also discuss these markers in other diseases namely cardiovascular disease 
which may account for a large proportion of deaths attributable to LRTI.

Literature discussed in this review was in part identified through a systematic literature search of English-language publications indexed in PubMed in March 2015 under the terms "lower respiratory tract infection" or "pneumonia" or "chronic obstructive pulmonary disease" combined with "mortality" with or without "prediction" and/or "cardiovascular risk" together with any of the terms "steroid hormones" or "biogenic amines" or "trimethylamine-Noxide" or "intermediates of energy metabolism" or "oxidative status" or "monosaccharides" or "sphingolipids" or "glycerophospholipids" or "acylcarnitines". Additionally, more specific keywords were used: "aldosterone", "androstenedione", "androsterone", "corticosterone", "cortisol", "cortisone", "dehydroepiandrosterone", "11-deoxycorticosterone", "dihydrotestosterone", "11-deoxycortisol", "dehydro-epiandrosterone-sulfate", "betaestradiol", "estrone", "eiocholanolone", "17-alpha-hydroxyprogesterone", "progesterone", "testosterone", "acetylornithine", "asymmetric dimethylarginine", "symmetric dimethylarginine", "alphaaminoadipic acid", "carnosine", "creatinine", "histamine", "kynurenine", "methioninesulfoxide", "nitrotyrosine", "cis4-hydroxyproline", "trans-4-hydroxyproline", "phenylethylamine", "putrescine", "sarcosine", "serotonin", "spermidine", "spermine", "taurine", "dopamine", "DOPA", "lactate", "3-phosphoglycerate", "alpha-ketoglutaric acid", "adenosine- 3 ' $5^{\prime}$-cyclic monophosphate", "arginine", "aspartate", "dihydroxyacetonephosphate", "fumarate", "glutamate", "hexose", "hexosephosphate", "pentosephosphate", "pyruvate", "succinate", "tetrosephosphate", "hexoses", "glutathione", "glutathione-disulfide", "cysteine", "cystine", "homocysteine", and "homocystine". Additional systematic reviews of the topic were included if they provided new insights and evidence. As shown in Fig. 1, 4722 of 4773 articles were excluded due to duplication, absence

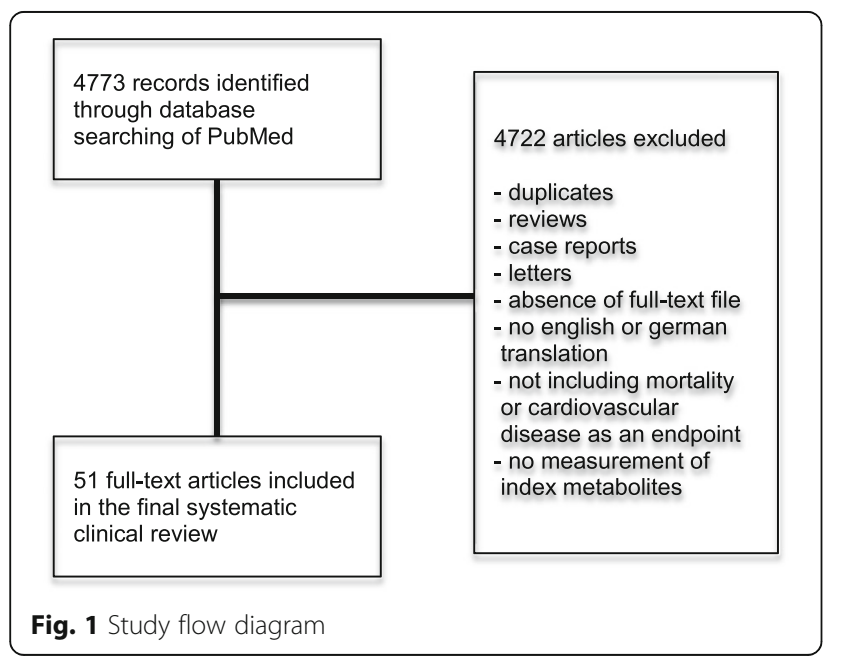

of full text or inappropriate contents. Letters and case reports were also excluded.

\section{Promising metabolic biomarkers for prediction of all-cause mortality \\ Steroid hormones \\ Pathway and physiological role}

Only few tissues contribute substantially to de novo steroid biosynthesis: primarily the adrenal glands, the gonads, and the placenta [43]. All steroid hormones are derived from cholesterol. Cholesterol enters the cell via lipoprotein-binding and is stored in cytoplasmic vacuoles. After binding of adrenocorticotropic hormone $(\mathrm{ACTH})$ to its receptor (melanocortin receptor type 2, MC2R) on adrenal cells, cholesterol is mobilized and thus available for steroid synthesis. Follicle-stimulating hormone $(\mathrm{FSH})$ is critical in estradiol synthesis before and during ovulation and Luteinizing hormone (LH) for synthesis of progesterone. In the placenta, steroid biosynthesis is dependent on human chorionic gonadotropin (hCG) in early gestation [43].

One of the first measurable physiopathological reactions to infection is the activation of the hypothalamopituitary-adrenal (HPA) axis via stimulation of the central noradrenergic stress system by cytokines and other mediators that are released in response to inflammation [44-46]. Under healthy conditions, cortisol secretion is synchronized with dehydroepiandrosterone (DHEA) in response to the release of $\mathrm{ACTH}$ and corticotropinreleasing hormone $(\mathrm{CRH})$, whereas in critically ill patients the circadian pattern of cortisol is lost [47] and DHEA and dehydroepiandrosterone-sulfate (DHEA-S) decrease [48]. Although the physiological role of DHEA and DHEA-S is not completely understood, there are clear indications that they modulate the immune response and influence proinflammatory and anti-inflammatory cytokine release [48-52]. In severely ill pneumonia patients, an intra-adrenal shift from DHEA-S to cortisol production occurs, which might be a potentially life-saving process during critical illness and thus important for survival in CAP [53]. Estradiol induces activation of macrophages and production of proinflammatory cytokines and chemokines from inflammatory cells [54-56], and testosterone has suppressive effects on immune responses, thereby inducing increased suceptibility to infection [57]. In autoimmune diseases progesterone shows proinflammatory and anti-inflammatory effects [58].

\section{Current research (Table 1)}

Table 1 lists several studies reporting that increased cortisol (free and total) levels measured at initial hospital presentation are independent predictors of in-hospital and short-term all-cause mortality in hospitalized patients with mild to severe CAP [53, 59-62]. Interestingly, 
Table 1 Summary of selected literature relevant to steroid hormones in all-cause mortality prediction

$\begin{array}{llll}\text { First author, Marker Study type } & \text { Study population findings }\end{array}$

Key findings

Limitations

\section{Mueller et al.,}

- Cortisol

Single-center, prospective

observational cohort study

(6-week follow-up)/secondary

chart analysis of a single-

179 prospectively recruited -1

- In age and gender adjusted logistic regression

analysis, cortisol (OR: $2.8 ; 95 \%$ Cl: 1.48-5.28,

$p=0.002)$ and DHEA (OR: $2.62 ; 95 \% \mathrm{Cl}$ :

$1.28-5.34, p=0.008)$, but not DHEA-S and

none of the different ratios (cortisol/DHEA

interventional study

- DHEA-S

cortisol/DHEA-s, DHEA/DHEA-S) were

associated with increased 6-week all-cause mortality; the discriminatory accuracy in ROC analysis (AUC) to predict mortality was 0.74 (95\% Cl: 0.60-0.88) for cortisol, $0.61(95 \% \mathrm{Cl}$ $0.46-0.75)$ for DHEA and 0.72 (95\% Cl: 0.62-0.81) for the PSI

Christ-Crain - Free cortiso et al., 2007, [59]

Multicenter, prospective observational cohort study (patients recruited from

984 hospitalized CAP patients, recruited from multicenter national CAPNETZ) (30-day follow-up) $6.9+/-1.9$ (6.9 +/-1.9-week follow-up)/ controlled interventional study patients presenting to the emergency department with CAP
Single-center, prospective single-center, randomized
Kolditz et al _ - Cortisol 2010, [61]
Single-center, prospective observational cohort study (30-day follow-up)
59 adult patients hospitalized with CAP
- Initial TC and FC levels were significantly higher in non-survivors than in survivors $(p<0.001$ for $\mathrm{TC}$ and $p=0.004$ for $\mathrm{FC}$ ); the area under the receiver operating characteristic curve (AUC) to predict death was $0.76(95 \%$ $\mathrm{Cl}, 0.70-0.81)$ for $\mathrm{TC}$ and $0.69(95 \% \mathrm{Cl}$, 0.63-0.74) for FC, whereas the AUC of the PS was $0.76(95 \% \mathrm{Cl}, 0.70-0.81)$ to predict mortality

- The prognostic accuracy of FC was not higher than the one for TC $(p=0.12)$

TC and FC levels were independent mortality predictors in pneumonia; the prognostic accuracy of total cortisol equaled the

predictive power of the PSI

- After a follow-up period of 30 days initial serum cortisol levels were significantly higher in non-survivors than in survivors $(p<0.001)$; the AUC to predict 30-day mortality was 0.70 (cut-off serum cortisol value $795 \mathrm{nmol} / \mathrm{l}$ )

- Predictive accuracy of the CURB-65 score alone (AUC 0.76) was significantly improved by combining with serum cortisol levels (AUC $0.81, p=0.001$ )

- Survival analysis by Kaplan-Meyer curves demonstrated a significantly different survival within cortisol-quartiles $(p<0.001)$, which persisted within individual CURB-65 classes $(p=0.002-0.003)$.

After a follow-up period of 30 days cortisol was significantly higher in non-survivors

compared to survivors $(p=0.009)$ and was an independent predictor of short-term mortality (OR 1.002, 95 \% Cl 1.000-1.004, $p=0.04$ )
- Single-center study

Secondary chart analysis of remaining blood samples; the study had not been prospectively designed to use adrenal hormone concentrations as a primary endpoint [139]

- Cortisol, DHEA-S and DHEA levels were measured at different times during the day

- This study had not been prospectively designed to use cortisol concentrations as a primary endpoint, and only single initial cortisol levels were measured [139]

- Cortisol levels were measured at different timepoints during the day

- No assessment of adrenal function

No correction for concomitant steroid medication, due to absent data

Since blood samples were taken at time of first contact, cortisol levels were measured at different time points during the day; however, during infectious diseases and thus increased stress levels the circadian pattern of cortisol production is often lost [140]

No assessment of adrenal function

Small sample size 
Table 1 Summary of selected literature relevant to steroid hormones in all-cause mortality prediction (Continued)

- DHEA

DHEA-S

Salluh et al., Total cortiso 2008, [62]

Cortés-Puch et al., 2014,

[63]
Single-center, prospective observational cohort study (follow-up until death (in-hospital mortality) or hospital discharge)
72 patients with severe CAP admitted to the ICU
- The prognostic accuracy of serum cortisol 734 nmol/) was similar to that of cortiso: 734 nmol/ was similar to that of the PSI of the CURB-65 score (AUC 0.68, $95 \%$ $0.50-0.85$ ) in predicting 30-day mortality

- Serum cortisol levels were independent 30-day mortality predictors in pneumonia, whereas DHEA and DHEA-S showed no significant difference between survivors and non-survivors ( $p=0.16$ and $p=0.70$ )

- TC levels were significantly higher in nonsurvivors compared to survivors ( $p=0.003$ for TC), whereas postcorticotropin cortisol levels and $\Delta$-cortisol achieved no significant difference between survivors and nonsurvivors ( $p \geq 0.05$, exact value not shown)

- Increases in mortality rates were observed across all quartiles of baseline TC levels

- The AUC to predict mortality was 0.77 (95\% Cl, 0.64-0.90; $p=0.002$; cut-off $25.7 \mu \mathrm{g} / \mathrm{dl}$ ) for TC, 0.60 for delta-cortisol (95\% Cl 0.42-0.78; $p=0.24), 0.58$ for postcorticotropin cortisol ( $95 \% \mathrm{Cl} 0.43-0.74 ; p=0.33$ ), 0.71 for CURB-65 (95\% Cl 0.57-0.86; $p=0.01$ ) and $0.71 \mathrm{for}$ APACHE II score (95\% Cl 0.56-0.86; $p=0.01)$ whereas baseline TC achieved a significantly higher AUC than postcorticotropin cortiso $(p=0.03)$

- Kaplan-Meier curves demonstrated serum baseline cortisol (TC) concentration of $>25.7 \mu \mathrm{g} / \mathrm{dl}$ on presentation to have a significantly higher risk of death (log rank test $p<0.001)$ compared to baseline cortisol levels below this cut-off $(p=0.019)$

- In univariate analysis, baseline cortisol, CURB-65 and APACHE II score were predictors of short-term mortality

101 canine suffering from S. aureus pneumoniainduced sepsis cortisol levels and change in cortisol levels after exogenous ACTH administration (delta (AUC $0.86[0.75-0.97]$ ) and superior to that

- Single-center study

No measurements of serum levels of free cortisol

Cortisol, DHEA and DHEA-S levels were measured at different timepoints during the day, which could limit the prognostic accuracy of one single cortisol value

DHEA-S shows age-dependent differences in secretion levels

Small sample size with a mortality rate of only $16.7 \%$ (12 patients), leading to low statistical power

\section{- Single-center study}

No data about patients with severe immunosuppression

No measurement of free cortisol levels

- Measurement of cortisol levels at different timepoints during the day, potentially limiting the prognostic accuracy of one single cortiso value

Potential confounding due to treatment with corticosteroids in the study population

\section{- Low sample size} cortisol) showed no significant difference between survivors and non-survivors $(p=0.75$ for TC, $p=0.80$ for FC, $p=0.64$ for delta cortisol after ACTH stimulation), whereas $\mathrm{ACTH}$ levels correlated significantly, but weakly, with mortality $10 \mathrm{~h}$ after onset of sepsis $(p=0.04)$
Cortisol responses may partly be attributed to sedation, intubation, mechanical ventilation, and repeated ACTH stimulation testing animal study (96-hour

follow-up) 
Table 1 Summary of selected literature relevant to steroid hormones in all-cause mortality prediction (Continued)

\begin{tabular}{|c|c|c|c|c|}
\hline & - ACTH & & & - At $24 \mathrm{~h}$ total and free cortisol, ACTH levels as \\
\hline & - Aldosterone & & & correlated significantly with \\
\hline \multirow{3}{*}{$\begin{array}{l}\text { Ohlsson et al., } \\
\text { 2010, [65] }\end{array}$} & - DHEA & \multirow{3}{*}{$\begin{array}{l}\text { Prospective observational } \\
\text { population-based cohort } \\
\text { study (mean } 4.5 \text {-year } \\
\text { follow-up) }\end{array}$} & \multirow{3}{*}{$\begin{array}{l}2644 \text { Swedish men from } \\
\text { the Swedish multicenter } \\
\text { Osteoporotic Fractures in } \\
\text { Men cohort }\end{array}$} & \multirow{2}{*}{$\begin{array}{l}\text { - Low levels of DHEA-S and DHEA (quartile } 1 \text { vs. } \\
\text { quartiles 2-4) predicted all-cause mortality } \\
\text { (multivariate adjusted HR } 1.54,95 \% \mathrm{Cl} \\
1.21-1.96 \text { for DHEA-S; HR } 1.48,95 \% \mathrm{Cl} \\
1.17-1.88 \text { for DHEA) }\end{array}$} \\
\hline & - DHEA-S & & & \\
\hline & & & & $\begin{array}{l}\text { - Age-adjusted risk of all-cause mortality was } \\
\text { increased in men within Q1 of DHEA and } \\
\text { DHEA-S levels compared with men within the } \\
\text { individual quartiles 2, } 3 \text { and } 4 \text { (Q2, Q3, Q4) } \\
\text { (Q1: HR 1.00 (referent); DHEA: Q2 vs. Q1 HR } \\
\text { 0.69, Q3 vs. Q1 HR 0.66, Q4 vs. Q1 HR 0.60; } \\
\text { DHEA-S: Q2 vs. Q1 HR 0.69, Q3 vs. Q1 0.71, } \\
\text { Q4 vs. Q1 0.60) }\end{array}$ \\
\hline \multirow[t]{2}{*}{$\begin{array}{l}\text { Hsu et al., } \\
\text { 2012, [66] }\end{array}$} & DHEA-S & \multirow[t]{2}{*}{$\begin{array}{l}\text { Single-center, prospective } \\
\text { observational cohort study } \\
\text { (mean follow-up time: } \\
38.2+/-20.4 \text { months) }\end{array}$} & \multirow[t]{2}{*}{$\begin{array}{l}200 \text { CKD patients (men) } \\
\text { on hemodialysis (HD) } \\
\text { more than } 6 \text { months }\end{array}$} & $\begin{array}{l}\text { - Low plasma DHEA-S levels (cut-off } 790 \mathrm{ng} / \mathrm{ml} \text { ) } \\
\text { showed significant association with increased } \\
\text { all-cause mortality (HR } 3.667,95 \% \mathrm{Cl} 1.710- \\
7.909 ; p=0.001 \text { ) in hemodialysis men, but not } \\
\text { in women (data not shown) }\end{array}$ \\
\hline & & & & $\begin{array}{l}\text { - Multivariate Cox regression analysis adjusted } \\
\text { for age, comorbidities such as diabetes } \\
\text { mellitus, chronic heart failure, COPD, CRP as } \\
\text { well as for albumin and creatinine } \\
\text { demonstrated an independent association } \\
\text { between low plasma DHEA-S levels and } \\
\text { all-cause mortality in HD men (HR 2.93, } 95 \% \\
\text { Cl 1.09-7.89; } p=0.033 \text { ) }\end{array}$ \\
\hline \multirow{3}{*}{$\begin{array}{l}\text { Feng et al., } \\
\text { 2014, [67] }\end{array}$} & - Estradiol & \multirow{3}{*}{$\begin{array}{l}\text { Single-center, prospective } \\
\text { observational cohort study } \\
\text { (28-day follow-up) }\end{array}$} & \multirow{3}{*}{$\begin{array}{l}107 \text { clinically diagnosed } \\
\text { pneumonia-related septic } \\
\text { shock patients }\end{array}$} & \multirow{2}{*}{$\begin{array}{l}\text { - Serum levels of progesterone and estradiol } \\
\text { were significantly higher in non-survivors } \\
\text { compared to survivors }(p<0.001) \text {, whereas } \\
\text { testosterone levels were similar in both } \\
\text { groups }(p=0.74)\end{array}$} \\
\hline & - Progesterone & & & \\
\hline & - Testosterone & & & $\begin{array}{l}\text { - The discriminatory accuracy in ROC analysis } \\
\text { (AUC) to predict } 28 \text {-day mortality was } 0.87 \\
\text { ( } p<0.001 \text { ) for the APACHE II score (cut-off } 26 \\
\text { points), } 0.705(p<0.001) \text { for estradiol (cut-off } \\
40 \mathrm{pg} / \mathrm{ml}), 0.713(p<0.001 \text { ) for progesterone } \\
\text { (cut-off } 1.03 \mathrm{ng} / \mathrm{ml} \text { ) and } 0.518(p=0.74) \text { for } \\
\text { testosterone (cut-off } 4.4 \mathrm{ng} / \mathrm{ml} \text { ) }\end{array}$ \\
\hline $\begin{array}{l}\text { Shores et al., } \\
\text { 2014, [68] }\end{array}$ & $\begin{array}{l}\text { - Total } \\
\text { testosterone }\end{array}$ & $\begin{array}{l}\text { Prospective observational } \\
\text { cohort study (9-year } \\
\text { follow-up) }\end{array}$ & $\begin{array}{l}1032 \text { men in the } \\
\text { Cardiovascular Health } \\
\text { Study (CHS) }\end{array}$ & $\begin{array}{l}\text { - Adjusted for age and cardiovascular risk } \\
\text { factors, low DHT }(<25 \mathrm{ng} / \mathrm{dl}) \text { and cFDHT } \\
(<0.13 \mathrm{ng} / \mathrm{dl}) \text { levels showed significant } \\
\text { associations with higher all-cause mortality, } \\
\text { even if adjusted for cardiovascular risk factors } \\
\text { (HR 1.31, } 95 \% \mathrm{Cl} 1.04-1.65 \text { for DHT; HR 1.72, }\end{array}$ \\
\hline
\end{tabular}

hevels as

-

correlated significantly with

Single measurement of DHEA and DHEA-S at different timepoints during the day with

subsequent possible diurnal variation in serum

DHEA and DHEA-S levels

No data about treatment with corticosteroids or other hormones, which might alter mortality risk and/or DHEA and DHEA-S levels

- Single-center study

No assessmet of testosterone levels as a precursor of DHEA-S

- Plasma DHEA-S levels were analyzed from one single pre-dialysis sample

- Single-center study

- Most of the patients participating in the study were male

No enrollment of premenopausal women

Blood sample collection for hormone measurements only on the first day of septic shock (no investigation of the dynamic of serum sex hormone levels during the course of disease)

\section{Only one single testosterone measurement}

- Time of day for blood collection was not standardized; however, the effects of these varying time points of blood collection might be minimal due to less circadian fluctuation in 
Table 1 Summary of selected literature relevant to steroid hormones in all-cause mortality prediction (Continued)

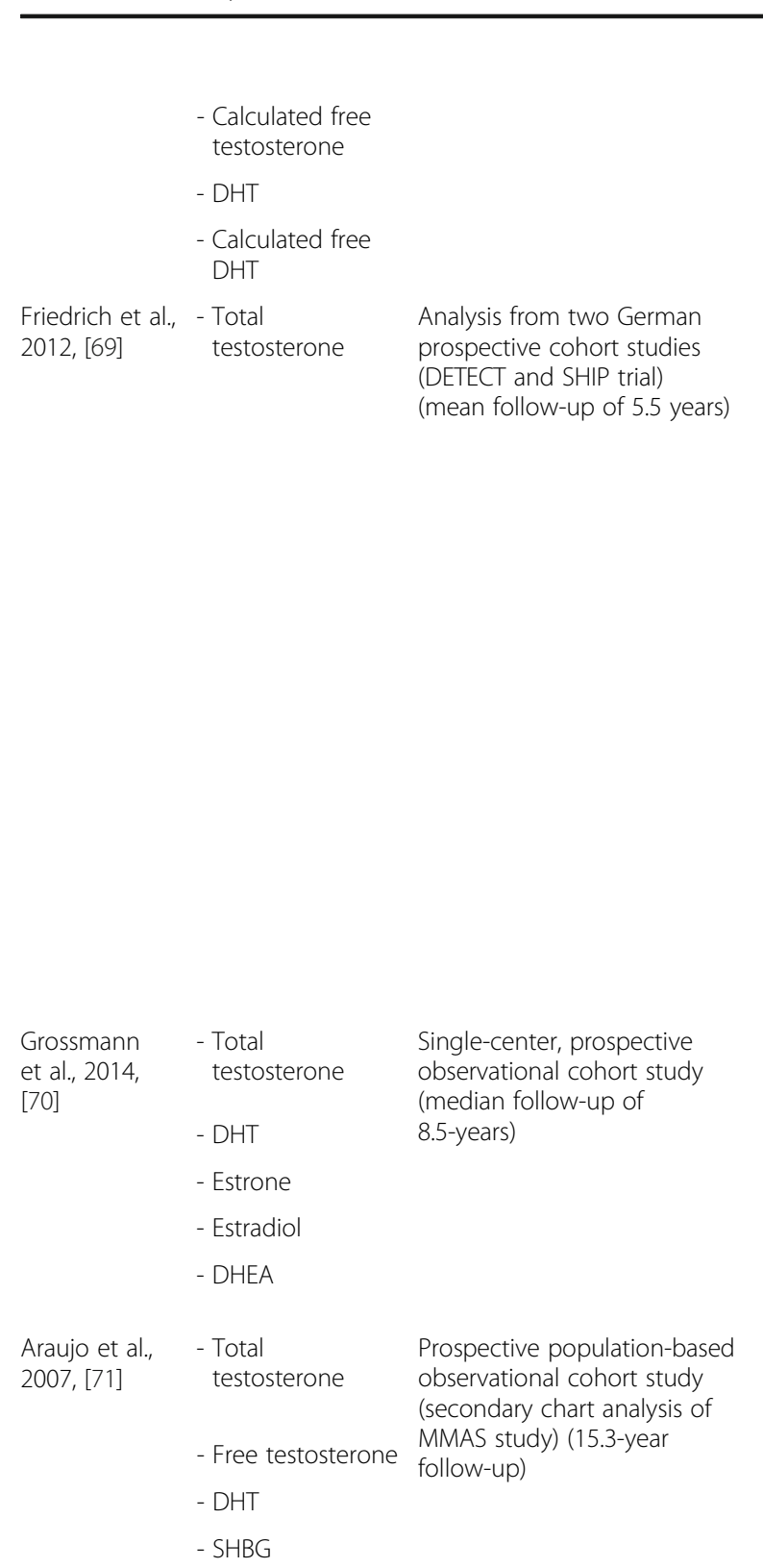

$95 \% \mathrm{Cl} 1.25-2.37$ for calculated free $\mathrm{DHT}$; $p<0.001$ for both)

$-T$ and cFT as well as SHBG were not

significantly associated with all-cause mortality (HR 1.05 (0.88-1.25) for testosterone; HR 1.04 (0.88-1.23) for cFT)

3942 men

Cox regression analyses adjusted for waist-toheight ratio, smoking and physical activity revealed that men with total serum

testosterone levels below the 10th percentile showed an increased independent risk of allcause mortality compared to subjects with higher hormone levels (HR 1.54, 95 \% Cl

$1.20-1.99, p<0.01$ ); by additional inclusion of liver disease, increased blood pressure, diabetes and hsCRP as confounders the results were still significant for the 10th

percentile as a cut-off (HR 1.38, $95 \%$ Cl 1.06$1.78, p=0.02$ ); using the 20th percentile as a cut-off resulted in no significant difference in all-cause morality between lower and higher testosterone levels (unadjusted model: HR

$$
1.25,95 \% \mathrm{Cl} 0.99-1.57, p=0.06)
$$

- In univariate Kaplan-Meier survival analysis patients with lower serum total testosterone levels (cut-off: 10th percentile) showed significantly higher all-cause mortality compared to subjects with non-low hormone levels $(p<0.01)$

221 patients with CKD IIII-IV, undergoing dialysis or KTR

Cox proportional hazards regression showed significant independant association between low total testosterone levels and high mortality rates $(p=0.01)$

- Low testosterone concentrations were independent mortality predictors in men, whereas sex steroid levels in women showed no significant association with all-cause mortality

1686 men aged 40 to 70 years, population-based randomly sampled

- In multivariate, age-adjusted models $T T$ levels as well as FT, DHT and SHBG were not significantly associated with all-cause mortality

Categorizing TT, FT, DHT and SHBG into 5 quintiles yielded no significant correlation with all-cause mortality either (for $T$ : reference group (RR=1): $T \geq 650 \mathrm{ng} / \mathrm{d}$ testosterone levels in older men and no

significant circadian variation of DHT levels [141]

$+2$

- Only one single serum total testosterone measurement at baseline

- Blood collection at different timepoints during the day; however, serum samples showed only minor differences in testosterone levels collected before and after noon; therefore the effect of the diurnal variation seems to be minimal

- Use of different assay systems to determine total testosterone

No measurement of SHBG and thus no calculation of free testosterone levels

- Small female sample size

- Single-center study

- No data about patients with CKD I-II

Inclusion of mostly white men of higher socioeconomic status; thus results may not be generalizable

No data about women in this study 
Table 1 Summary of selected literature relevant to steroid hormones in all-cause mortality prediction (Continued)

< 370 ng/dl: RR 1.24 (95 \% Cl 0.89-1.73);

$370-466 \mathrm{ng} / \mathrm{dl}$ : RR 1.00 (95\% Cl 0.70-1.42);

$466-545 \mathrm{ng} / \mathrm{dl}:$ RR 1.05 (95\% Cl $0.74-1.47)$

$545-650 \mathrm{ng} / \mathrm{dl}:$ RR 1.20 (95\% Cl 0.86-1.69)

$(p$ for trend $=0.50)$ )

Lowest quintile of free testosterone level was

significantly associated with decreased IHD

mortality ( $p$ for trend $=0.02$ ) and increased

respiratory disease mortality ( $p$ for trend $=$

0.002);

- In conclusion, TT and FT as well as DHT seem

to have a relatively weak or no association

with all-cause mortality

$\begin{array}{llll}\text { De Padua } & \text { Estrone } & \begin{array}{l}\text { Single-center, prospective } \\ \text { observational cohort study } \\ \text { Mansur et al., }\end{array} & \begin{array}{l}251 \text { postmenopausal } \\ \text { women in the ambulatory } \\ \text { (5012, [72] }\end{array} \\ \begin{array}{ll}\text { care clinic of a tertiary } \\ \text { cardiology hospital }\end{array}\end{array}$

- Kaplan Meier survival curve showed a

significant association between higher allcause mortality in women and low estrone levels $(<15 \mathrm{pg} / \mathrm{ml})(p=0.039)$

- Multivariate Cox regression analysis adjusted for diabetes, body mass index, dyslipidemia, and family history showed estrone to be the only independent predictor for all-cause mortality (OR 0.45 (95 \% Cl 0.21-0.95);

$p=0.038)$

Single-center study

- No data about male patients

Only 32 deaths and thus relatively low statistical power

ACTH adrenocorticotropic hormone, APACHE II Acute Physiology And Chronic Health Evaluation, ApoE apolipoprotein E, AUC area under the receiver operating characteristic curve, CAD coronary artery disease, CAP community-acquired pneumonia, CAPNETZ network of excellence community-acquired pneumonia, Germany, CFDHT calculated free dihydrotestosterone, CFT calculated free testosterone, CHS Cardiovascular Health Study, Cl confidence interval, CKD chronic kidney disease, COPD chronic obstructive pulmonary disease, CRP C-reactive protein, CURB-65 score new-onset confusion urea $>7 \mathrm{mmol} / \mathrm{L}$ respiratory rate $\geq 30$ breaths per minute systolic or diastolic blood pressure $<90 \mathrm{mmHg}$ or $\leq 60 \mathrm{mmHg}$ respectively age $\geq 65$ years (pneumonia/LRTI risk scoring system), CVD cardiovascular disease, DETECT Diabetes Cardiovascular Risk-Evaluation: Targets and Essential Data for Commitment of Treatment, DHEA dehydroepiandrosterone, DHEA-S dehydroepiandrosterone-sulfate, DHT dihydrotestosterone, $F C$ free cortisol, $F T$ free testosterone, HD hemodialysis, HR hazard ratio, hsCRP high-sensitive C-reactive protein, ICU intensive care unit, IHD ischemic heart disease, IL-1beta interleukin-1 beta, KTR kidney transplant recipients, LDL low-density lipoprotein, MMAS Massachusetts Male Aging Study, OR odds ratio, $p$-value are statistically significant at $p<0.05, P S /$ pneumonia severity index, $Q$ quartile, $R O C$ receiver operationg characteristic, $R R$ relative risk, sd-LDL small dense low-density lipoprotein, SHBG sex hormone binding globuline, SHIP Study of Health in Pomerania, TC total cortisol, $\pi$ total testosterone, VLDL very-low-density lipoprotein 
the predictive accuracy of free cortisol (FC) is equal to that of total cortisol (TC) in pneumonia, independent of serum albumin levels [59]. The prognostic accuracy of cortisol in predicting mortality is equal to that of the PSI, but higher compared to routinely measured laboratory parameters such as CRP, PCT or leukocytes, which do not show significant differences $(p>0.05)$ [59-61]. Kolditz et al. observed that serum cortisol levels may noticeably improve the predictive power of the CURB-65 score alone as regards short-term mortality [60, 61]. Salluh et al. demonstrated that compared to baseline serum cortisol levels, which are proven independent mortality predictors, neither postcorticotropin cortisol nor $\Delta$-cortisol has notable predictive power in severe CAP [62]. A recent animal study of canines suffering from staphylococcus aureus pneumonia showed that ACTH stimulation induces a pronounced correlation between all-cause mortality and cortisol (free and total) levels and $\Delta$-cortisol [63].

Conflicting results mark studies evaluating the role of serum DHEA as a mortality predictor. A prospective clinical trial conducted by Mueller et al. demonstrated that increased DHEA predicts 6-week mortality in CAP, whereas blood levels of DHEA-S as well as different ratios between cortisol and DHEA, cortisol and DHEA-S, and DHEA and DHEA-S shows no significant correlation with all-cause mortality [53]. Contrary to these findings, Kolditz et al. found no difference in DHEA levels in non-survivors compared to survivors, whereas the lack of significance for the ratio between DHEA and DHEA-S as a mortality predictor accords with the results of Mueller et al. [53, 61]. Data on patients suffering from sepsis reveal a noticeable dissociation between cortisol and DHEA in non-survivors compared to survivors, and from this observation it can be inferred that an increased cortisol/DHEA ratio is a prognostic marker in sepsis [64]. However, although the cortisol/DHEA ratio in clinical studies of CAP patients is not significant in the prediction of mortality, nevertheless, in nonsurvivors an increased cortisol/DHEA ratio occurs as a tendency [53]. In elderly Swedish men, an inverse association between serum DHEA and DHEA-S is evident, whereas low serum DHEA and high DHEA-S levels are independent predictors of all-cause mortality [65]. Furthermore $\mathrm{Hsu}$ et al. demonstrated a marked and independent association between low levels of plasma DHEA-S and higher mid-term all-cause mortality in men with chronic kidney disease (CKD) who were undergoing hemodialysis [66].

Table 1 depicts the strong association between increased serum estradiol and progesterone levels and 28-day mortality in patients suffering from pneumoniarelated septic shock, whereas serum testosterone levels are not noticeably different between survivors and non- survivors after a 28-day follow-up [67]. A prospective clinical study of elderly men who were free of cardiovascular disease at the time of blood sample collection, revealed a significant inverse association between dehydrotestosterone (DHT) and calculated free DHT levels with all-cause mortality during a follow-up period of 9 years, whereas total testosterone and calculated free testosterone showed no significant correlation with mortality [68]. Contrary to these findings, Friedrich et al. and Grossmann et al. observed that low serum total testosterone levels in men with and without CKD significantly and independently predict all-cause mortality $[69,70]$, whereas another population-based clinical study of 40- to 70-yearold men [71] observed no significant association with either total or free testosterone, or with DHT in all-cause mortality in multivariate-adjusted analysis.

In postmenopausal women low estrone levels independently predict long-term all-cause mortality [72].

\section{Biogenic amines}

I. L-arginine metabolites: Asymmetric dimethylarginine and symmetric dimethylarginine

Pathway and physiological role Endothelial nitric oxide synthases (NOS) synthesize nitric oxide (NO) from $\mathrm{L}$-arginine (Arg). NO is responsible for vasodilatation and acts as a neurotransmitter with several functions, including memory formation [73]. NO promotes relaxation of airway smooth muscle in the respiratory system, but NO deficiency results in hyperreactivity of the airway [74]. Asymmetric dimethylarginine (ADMA) and its isomer symmetric dimethylarginine (SDMA) are endogenous compounds of methylated protein turnover. ADMA-but not SDMA-is a competitive inhibitor of NOS and thus indirectly of NO [75]. One study shows that ADMA is present in the sputum of COPD patients [76].

Current research (Table 2) A large community-based study of middle-aged participants revealed a positive association between ADMA levels and long-term mortality, whereas the Arg/ADMA ratio was inversely associated with death rate [77]. In people $>65$ years, ADMA is the strongest predictor of all-cause mortality, while some traditional risk factors-e.g., body mass index, systolic and diastolic blood pressure, male sex or triglycerides-lose their predictive power in this age group [78]. Additionally, elevated ADMA and SDMA serum levels correlate noticeably with higher all-cause mortality in patients with stable CHD [79] and in critically ill patients $[80,81]$. Contrary to these findings, another study-after adjustment for NT-proBNP, hsCRP, troponin $\mathrm{T}$ and cardiorenal indices-reveaed that SDMA, but not ADMA, is an independent predictor of all-cause mortality [82]. 
Table 2 Summary of selected literature relevant to biogenic amines in all-cause mortality prediction

First author, Marker Study type Study population

year, reference

Study population

Key findings

Limitations

\begin{tabular}{lll}
\hline Böger et al., 2009, [77] & - ADMA & $\begin{array}{l}\text { Observational, prospective } \\
\text { cohort study (median }\end{array}$
\end{tabular}
follow-up of 10.9-year)

Pizzarelli et al., 2013, [78] - ADMA

- L-arginine
Single-center, prospective cohort study (median follow-up of 110 months)
3,319 middle-aged participants
(Framingham Offspring Study)

25 randomly selected adults $>65$ years) living in Chianti area Tuscany, Italy
Siegerink et al., 2013, [79] - ADMA

- SDMA

Koch et al., 2013, [80]
Multicenter, observational, prospective cohort study (median follow-up o

8.1 years)

Single-center, observational prospective cohort study (3-year follow-up)
1,148 subjects suffering from myocardial infarction/ACS, or undergoing cardiac surgery due to CHD

(KAROLA Study, Germany)

255 ICU patients and 78 healthy controls living in Germany
ADMA was positively associated with

mortality (multivariable-adjusted HR 1.21 $95 \%$ Cl 1.07-1.37, $p=0.003$ )

Arginin/ADMA-ratio was inversely associated with mortality (HR 0.80, $95 \%$ Cl $0.69-0.93, p=0.004)$

- Higher ADMA levels $(p=0.0002)$ and lower Arg/ADMA-ratios $(p=0.0005)$ were associated with elevated mortality in non-diabetic subjects

- Plasma ADMA was a strong predictor of all-cause mortality (HR 1.26, $95 \% \mathrm{Cl}$ $1.10-1.44, p<0.001$ ) and there was a non-significant trend for cardiovascular mortality (HR 1.22, $p=0.07)$ after multivariate adjusment

There was no association of ADMA with mortality in subjects with high L-arginine, but an increase in mortality in those with normal to low L-arginine

\section{- After adjustment for confounders higher} levels of ADMA (HR 1.15, $95 \%$ Cl 0.95-1.37) and SDMA (HR 1.29, $95 \% \mathrm{Cl} 1.09-1.52$ ) were associated with an increase in all-cause mortality

- ICU patients had higher serum ADMA levels than healthy controls (median 0.48 vs. 0.36 $\mu \mathrm{mol} / \mathrm{L}, p<0.001$

ICU non-survivors had higher ADMA levels compared with ICU survivors (median 0.62 vs. $0.44 \mu \mathrm{mol} / \mathrm{L}, p<0.001$ )

- High ADMA levels predicted all-cause mortality in critically ill patients $(p<0.001)$

- ADMA levels increased during 7 days of ICU therapy $(p<0.001)$

- ICU patients had higher serum SDMA levels than healthy controls (median 0.84 vs. 0.38 $\mu \mathrm{mol} / \mathrm{L}, p<0.001$ )

- ICU non-survivors had higher SDMA levels compared with ICU survivors (median $1.33 \mathrm{vs} .0 .74 \mu \mathrm{mol} / \mathrm{L}, p=0.001$ )
Single-center, observational 247 ICU patients and 84 healthy prospective cohort study controls living in Germany
- Single-center study

- Only one ethnic population
- Only middle-aged subjects

\section{- Selection bias}

- Only two-center study

- Short-term

intensive care

( $<72$ h) patients

were excluded

- Single-center study
- Short-term

intensive care

$(<72 \mathrm{~h})$

excluded

- Single-center study 
Table 2 Summary of selected literature relevant to biogenic amines in all-cause mortality prediction (Continued)

\begin{tabular}{|c|c|c|c|c|c|}
\hline & & (3-year follow-up) & & $\begin{array}{l}\text { - High SDMA levels predicted poorer long-term } \\
\text { prognosis in critically ill patients }(p<0.001)\end{array}$ & \\
\hline \multirow[t]{2}{*}{ Gore et al., 2013, [82] } & - SDMA & \multirow{2}{*}{$\begin{array}{l}\text { Observational prospective } \\
\text { cohort study (median } \\
\text { follow-up of } 7.4 \text { years) }\end{array}$} & \multirow{2}{*}{$\begin{array}{l}3,523 \text { adults aged } 30 \text { to } 65 \text { years } \\
\text { (Dallas Heart Study) }\end{array}$} & \multirow{2}{*}{$\begin{array}{l}\text { - After adjustment for cardiorenal indices, } \\
\text { age, sex, race, NT-proBNP, hsCRP and } \\
\text { Troponin, SDMA, but not ADMA, was } \\
\text { associated with all-cause mortality (HR } \\
\text { 1.86, } 95 \% \mathrm{Cl} 1.04-3.30, p=0.01 \text { ) }\end{array}$} & \multirow[t]{2}{*}{ - Single blood sampling } \\
\hline & - ADMA & & & & \\
\hline \multirow[t]{5}{*}{ Suzuki et al., 2011, [85] } & - Kynurenine & \multirow{5}{*}{$\begin{array}{l}\text { Single-center, observational } \\
\text { prospective cohort study }\end{array}$} & \multirow{5}{*}{$\begin{array}{l}129 \text { Japanese patients with CAP } \\
\text { and } 64 \text { healthy controls }\end{array}$} & \multirow{3}{*}{$\begin{array}{l}\text { - CAP patients had elevated levels of Kyn } \\
(p<0.0001) \text { and reduced levels of Trp } \\
(p<0.0001) \text { compared with healthy controls } \\
\text { and thus higher Kyn/Trp ratios ( } p<0.0001)\end{array}$} & - Single-center study \\
\hline & \multirow[t]{4}{*}{ - Tryptophan } & & & & - Small sample size \\
\hline & & & & & \multirow{3}{*}{$\begin{array}{l}\text { - No information about } \\
\text { duration of follow-up }\end{array}$} \\
\hline & & & & $\begin{array}{l}\text { - Increasing severity of sepsis and CAP (PSI } \\
\text { and CURB-65 score) was associated with higher } \\
\text { Kyn levels, lower Trp levels and higher Kyn/Trp ratios. }\end{array}$ & \\
\hline & & & & $\begin{array}{l}\text { - Non-survivors had higher Kyn levels } \\
(p=0.023) \text { and lower Trp levels }(p=0.032) \\
\text { and as a result, higher Kyn/Trp ratios } \\
(p=0.005)\end{array}$ & \\
\hline \multirow[t]{4}{*}{ Darcy et al., 2011, [86] } & - Kynurenine & \multirow{2}{*}{$\begin{array}{l}\text { Single-center, observational } \\
\text { prospective cohort study }\end{array}$} & \multirow{4}{*}{$\begin{array}{l}50 \text { patients from Australia with } \\
\text { severe sepsis (organ dysfunction } \\
\text { or shock), } 30 \text { with non-severe } \\
\text { sepsis and } 40 \text { hospital controls }\end{array}$} & \multirow{2}{*}{$\begin{array}{l}\text { - Sepsis patients had elevated levels of Kyn } \\
(p<0.0001) \text { and reduced levels of Trp }(p<0.0001) \\
\text { and thus higher Kyn/Trp ratios }(p<0.0001) \\
\text { compared with hospital controls. }\end{array}$} & - Single-center study \\
\hline & \multirow[t]{3}{*}{ - Tryptophan } & & & & \multirow[t]{3}{*}{ - Small sample size } \\
\hline & & \multirow[t]{2}{*}{ (28-day follow-up) } & & $\begin{array}{l}\text { - Kyn/Trp ratio was increased in severe } \\
\text { sepsis compared with non-severe sepsis } \\
(p=0.0006)\end{array}$ & \\
\hline & & & & $\begin{array}{l}\text { - Kyn/Trp ratio did not differ between survivors } \\
\text { and non-survivors by day } 28 \text { of the study }(p=0.2)\end{array}$ & \\
\hline \multirow[t]{2}{*}{ Huttunen et al., 2010, [87] } & - Kynurenine & \multirow{2}{*}{$\begin{array}{l}\text { Single-center, observational } \\
\text { prospective cohort study } \\
\text { (30-day follow-up) }\end{array}$} & \multirow{2}{*}{$\begin{array}{l}132 \text { patients with bacteremia } \\
\text { admitted to Tampere University } \\
\text { Hospital in Finland }\end{array}$} & \multirow{2}{*}{$\begin{array}{l}\text { - Maximum Kyn/Trp ratios were significantly } \\
\text { elevated in non-survivors ( } 30 \text {-day case fatality) } \\
\text { compared with survivors (193.7 vs. } \\
82.4 \mu \mathrm{mol} / \mathrm{mmol} ; p<0.001 \text { ) }\end{array}$} & - Small sample size \\
\hline & - Tryptophan & & & & - Single-center study \\
\hline \multirow[t]{3}{*}{ Qian et al., 2013, [92] } & \multirow[t]{3}{*}{ 3-nitrotyrosine } & \multirow{3}{*}{$\begin{array}{l}\text { Single-center, observational } \\
\text { prospective cohort study } \\
\text { (90-day follow-up) }\end{array}$} & \multirow{3}{*}{$\begin{array}{l}158 \text { patients with AKI, } 12 \text { critically } \\
\text { ill patients without AKI, } 15 \text { healthy } \\
\text { controls }\end{array}$} & \multirow{2}{*}{$\begin{array}{l}\text { - Patients with AKI had higher 3-NT/Tyr levels than } \\
\text { healthy and critically ill controls }(p<0.001)\end{array}$} & - Relatively small size study \\
\hline & & & & & \multirow{2}{*}{ - Single-center study } \\
\hline & & & & $\begin{array}{l}\text { - High 3-NT/Tyr was associated with higher 90-day } \\
\text { mortality }(p=0.025)\end{array}$ & \\
\hline
\end{tabular}

3-NT 3-nitrotyrosine, ACS acute coronary syndrome, ADMA asymmetric dimethylarginine, AKI acute kidney injury, CAP community-acquired pneumonia, CHD coronary heart disease, CI confidence interval, CURB-65 score new-onset confusion, urea $>7 \mathrm{mmol} / \mathrm{L}$, respiratory rate $\geq 30$ breaths per minute, systolic or diastolic blood pressure $<90 \mathrm{mmHg}$ or $\leq 60 \mathrm{mmHg}$, respectively, age $\geq 65$ years (pneumonia/LRTI risk scoring system), $H R$ hazard ratio, hsCRP high-sensitivity C-reactive protein, ICU intensive care unit, KAROLA Langzeitfolge der KARdiOLogischen Anschlussheilbehandlung, Germany, Kyn kynurenine, NT-proBNP pro-B-type natriuretic peptide, $p$-value are statistically significant at $p<0.05, P S /$ pneumonia severity index, SDMA symmetric dimethylarginine, Trp tryptophan, Tyr tyrosine 


\section{Kynurenine}

Pathway and physiological role Tryptophan (Trp) is an essential amino acid. Degradation of Trp to its toxic metabolite kynurenine (Kyn) is catalyzed by the enzyme indoleamine 2,3-dioxygenase (IDO), which is expressed in a variety of cells; e.g., monocyte-derived macrophages and dentritic cells [83]. Moreover, IDO induces inhibition of T-cell proliferation [84] and its activity is measured by the kynurenine-to-tryptohan ratio (Kyn/Trp ratio) [85-87].

Current research (Table 2) Subjects with CAP [85] and sepsis [86] show significantly higher Kyn levels and lower Trp levels compared to controls. As a result, the Kyn/Trp ratio, which represents the IDO activity, is elevated in CAP and sepsis $[85,86]$. Increased severity of CAP (defined by PSI and CURB-65 score) [85] and of sepsis [86] are associated with higher Kyn levels, higher Kyn/Trp ratios and lower Trp levels. In patients with CAP [85] or bacteremia [87], short-term non-survivors have higher Kyn/Trp ratios than do survivors, whereas the sepsis group manifests no marked difference in Kyn/ Trp ratio between non-survivors and survivors in the short-term [86].

\section{Nitrotyrosine}

Pathway and physiological role Homeostatic balance is usually maintained between the formation of reactive oxygen species (ROS) and its removal by endogenous antioxidants. Oxidative stress arises from an imbalance towards ROS production [88]. Peroxynitrite $\left(\mathrm{ONOO}^{-}\right)$is a potent oxidant of this ROS group and catalyzes nitration of the non-essential amino acid tyrosine (Tyr) to the non-proteinogenic amino acid 3-nitrotyrosine (3NT) [89]. Accordingly, nitrotyrosine is a characteristic marker of oxidative stress (e.g., inflammation) [90].

Protein-associated nitrotyrosine is lower in smokers than in non-smokers, evidence consistent with a lower production of endothelial NO in cigarette smokers. In contrast, smokers with COPD show higher average nitrotyrosine levels in plasma proteins compared with smokers without COPD. Therefore, it seems that chronic inflammatory processes in COPD patients increase the nitration of Tyr [91].

Current research (Table 2) As shown in Table 2, subjects with hospital-acquired acute kidney injury (AKI) have higher 3-nitrotyrosin/tyrosine ratios (3-NT/Tyr) than do critically ill subjects without AKI and healthy controls. In the AKI group, the $3-\mathrm{NT} / \mathrm{Tyr}$ ratio is positively associated with 90-day mortality independent of the severity of illness [92].

\section{Trimethylamine- $\mathrm{N}$-oxide, betaine, choline}

Pathway and physiological role Synthesis of phospholipids to build cell membranes, acetylcholine for neurotransmission just as the methyl group metabolism depend on dietary phosphatidylcholine (PC)/choline intake [93]. The liver and kidney can both oxidize choline to betaine. Betaine is an important metabolite in methyl group metabolism; it functions as a methyl group donor to form methionine [94, 95]. Eggs, red meat, beef and chicken liver, wheat germ, bacon, dried soy beans and pork contain the highest concentration of total choline. Betaine levels are high in wheat bread, wheat bran, wheat germ, spinach and shrimp [96]. Intestinal microbes (gut microflora) transform choline and other quaternary ammonium compounds (e.g., betaine) to the gas trimethylamine (TMA) [97]. This gas is reabsorbed efficiently into the circulation and then into human liver. Hepatic flavin-containing monooxygenases (FMOs) rapidly oxidize TMA to trimethylamine- $N$-oxide (TMAO) [98]. Thus TMA is not produced via intermediary metabolism; rather, it depends on intestinal microbial breakdown of choline and other precursors. Thus for the production of TMA and its oxidation product TMAO, intact and functional intestinal microflora are essential [97, 99].

Current research (Table 3) Several animal studies show the effects of elevated TMAO levels. An increase in the concentration of plasma TMAO was observed in mice, which were fed with either choline or TMAO [99, 100]. After 16 weeks of feeding there was a marked increase in tubulointerstitial fibrosis and serum cystatin C [100]. A significant positive correlation between plasma levels of TMAO and atherosclerotic plaque size after 20 weeks of feeding in both male and female mice was observed. Furthermore, macrophages from mice supplemented with either choline, betaine or TMAO showed augmented lipid-loaded macrophages and higher levels of the macrophage scavenger receptors CD36 and SRA1. These receptors implicate atherosclerosis. In a mouse model, application of broad-spectrum antibiotics for 3 weeks suppressed dietary choline-induced formation of macrophage foam cells and cholinemediated enhancement in atherosclerosis [99].

In humans (3), higher plasma NT-proBNP [101, 102] and advanced left ventricular diastolic dysfunction are associated with elevated plasma betaine, choline and TMAO. TMAO levels are markedly higher in patients with heart failure NYHA III/IV or diabetes mellitus. Baseline plasma levels of TMAO have marked prognostic value for major adverse cardiovascular events in lowrisk subgroups after adjustments for age and cardiorenal indices [102, 103]. Since cardiovascular disease (CVD) remains the major cause of deaths [104], these findings might be predictive of poor outcome. In addition, 
Table 3 Summary of selected literature relevant to trimethylamine-N-oxide in all-cause mortality prediction

First author, Marker Study type

Key findings

Limitations

year, reference

\begin{tabular}{llll}
\hline Tang et al.., & TMAO & $\begin{array}{l}\text { Single-center, prospective observational } \\
\text { cohort-study (5-year follow-up) }\end{array}$ & $\begin{array}{l}112 \text { adults with stable but symptomatic } \\
\text { chronic systolic HF (left ventricular ejection }\end{array}$ \\
c102] & & froctic
\end{tabular}
fraction $\leq 35 \%$ ) (Cleveland Clinic)

- After adjustment for age, eGFR, and NT-proBNP

- Single-center study

2015, [102] cohort-study (5-year follow-up)

levels, higher TMAO levels were associated with poor prognosis (death/transplantation) (HR 1.46;

- Selection bias

$95 \% \mathrm{Cl} 1.03-2.14 ; p=0.03)$

- TMAO levels were higher in subjects with higher plasma NT-proBNP levels and NYHA functional class III or IV ( $p=0.02)$

Tang et al.,

2013, [103]

TMAO Single-center, prospective interventional study (9-day follow-up)

40 healthy adults without chronic illnesses, active Infections or antibiotic therapy (Cleveland Clinic)

Tang et al.,

2013, [103]

TMAO Single-center, prospective observational cohort-study (3-year follow-up)

4,007 adults undergoing elective diagnostic cardiac catheterization without evidence of an ACS (Cleveland Clinic)

Tang et al.., 2014, [101]

Tang et al.., 2015, [100]
TMAO Single-center, prospective observational 521 subjects with CKD (eGFR $<60 \mathrm{~mL} / \mathrm{min}$ ) and cohort-study (5-year follow-up)
521 subjects with CKD (eGFR $<60 \mathrm{~mL} / \mathrm{min})$
- Increasing plasma levels of TMAO after oral phosphatidylcholine challenge

- In 6 adults, plasma levels of TMAO were markedly suppressed after a weekly therapy with broad-spectrum antibiotics and reappeared after withdrawal of antibiotics.

- Elevated plasma levels of TMAO were associated with a higher risk of a major cardiovascular event after adjustment for traditional risk factors $(p<0.001)$

- Prognostic value of elevated plasma levels of TMAO remained significant in low-risk subgroups

- Subjects with HF (5.0 $\mu$ mol) had higher median TMAO levels than subjects without HF $(3.5 \mu \mathrm{mol}$ $p<0.001$ )

- Small study population

- Only healthy adults included

- Single-center study - Selection bias

- TMAO levels were predictive of 5-year mortality risk after adjustments for traditional risk factors, BNP levels and eGFR (HR 1.75; $95 \%$ Cl 1.07-2.86; $p<0.001$ )

- TMAO levels were increased in CKD subjects (median, $7.9 \mu \mathrm{mo} / \mathrm{L}$ ) compared with non-CKD subjects (median, $3.4 \mu \mathrm{mol} / \mathrm{L}$ ), $p<0.001$

- Higher TMAO levels (quartiles 4 versus 1) were associated with an increase in 5 -year all-cause mortality in CKD subjects (HR 1.93; $95 \%$ Cl $1.13-3.29 ; p<0.05$ ) and non-CKD subjects after adjustment for traditional CVD risk factors and eGFR (HR 1.47; $95 \%$ Cl 1.02-3.29; $p<0.05$ )
- Single-center study

- Selection bias

No specific results for CKD stage 1-2

- Single-center study 
elevated TMAO levels are predictive of 5-year mortality risk in subjects with heart failure after adjustment for cardiovascular risk factors and renal function [101].

In healthy adults a dietary PC challenge raises TMAO level. In six human participants this elevation was suppressed with oral broad-spectrum antibiotics [103].

A high correlation is evident between plasma and urine levels of TMAO, which indicates an effective urinary clearance of TMAO [103]. Median TMAO blood levels in subjects with CKD stage 3 or beyond are markedly higher than in non-CKD subjects. Moreover, there is a modest correlation between elevated TMAO with low estimated glomerular filtration rate (eGFR) and high cystatin C. After adjustment for traditional cardiovascular risk factors an increased all-cause mortality rate at 5 years for CKD subjects with a higher TMAO level is evident. In subjects with preserved eGFR $(>60 \mathrm{~mL} / \mathrm{min}$ per $1.73 \mathrm{~m}^{2}$ ) higher TMAO levels are associated with higher 5 -year mortality, particularly in patients who have concomitant high cystatin C levels [100].

\section{Intermediate energy metabolism \\ Lactate}

Pathway and physiological role Glycolysis produces the metabolite pyruvate. Lactate dehydrogenase (LDH) converts pyruvate to lactic acid under anaerobic conditions. Lactate acid dissociates spontaneously to lactate and $\mathrm{H}^{+}$in aqueous solutions. Thus lactate is the end product of anaerobic glucose metabolism in erythrocytes, perivenous hepatocytes, skeletal myocytes and skin cells. A normal plasma lactate concentration is 0.3$1.3 \mathrm{mmol} / \mathrm{L}$ and the liver removes $70 \%$ of the lactate. An imbalance between systemic oxygen demand and oxygen availability (e.g., hypoperfusion in patients with sepsis) heightens anaerobic metabolism and results in lactic acidosis $[105,106]$.

Current research (Table 4) In children with pneumonia, relative risk for in-hospital mortality is higher if the lactate level is above $2 \mathrm{mmol} / \mathrm{L}$ [107]. In adults with pneumonia, lactate level is the better predictor of 28-day mortality than the CURB-65 score, whereas a combination of CURB-65 with lactate level improves the predictive value of CURB-65 alone (Table 4) [108].

Lactate $>3.5 \mathrm{mmol} / \mathrm{L}$ in combination with a $\mathrm{P}_{\mathrm{a}} \mathrm{O}_{2} / \mathrm{FiO}_{2}$ (PF) ratio $<170$ is associated with a higher 28 -day mortality rate; accordingly, a combination of serum lactate and the PF ratio may be a useful predictor of mortality in patients with sepsis, including pneumonia [109]. Metabolic profiling of plasma from 90 critically ill intensive care unit (ICU) patients revealed significantly higher lactate levels in non-survivors compared with survivors in 28-day mortality [110].

\section{Monosaccharides}

Pathway and physiological role Monosaccharides are the simplest form of sugar and therefore the most basic units of carbohydrates; they are important as an energy resource. The most important monosaccharides in human metabolism are the three aldohexoses (Dglucose, D-mannose, and D-galactose), and D-fructose, a sugar monomer of the ketohexose series of carbohydrates [111].

Current research (Table 5) In patients with CAP (Table 5), hypoglycemia [112] and hyperglycemia are associated with a higher rate of in-hospital mortality [112, 113] and in-hospital complications [113]. Furthermore, hyperglycemia is a predictor of death at 28 and 90 days after admission to hospital in patients with CAP and no pre-existing diabetes [114].

\section{Oxidative status}

Pathway and physiological role Reactive oxygen species (ROS) and reactive nitrogen species (RNS) are important in regulating the proliferation of cells and their survival. However, a sudden and prolonged surge of ROS and RNS may contribute to cell death. The redox homeostasis of cells, which maintains a balance between the generation and elimination of ROS and RNS ensures that endogenous and exogenous stimuli are modulated. Altered redox homeostasis leads to oxidative stress, which may cause aberrant cell death and the development of disease [115]. Glutathione (gamma-glutamylcysteinyl-glycine, GSH) is the predominant antioxidant non-protein cysteine-containing thiol, which is found in all animal cells. It is important in maintaining the status of cellular redox, which is determined by the ratio of the concentration of oxidizing equivalents to reducing equivalents [116], and it is the principal intracellular defense against oxidative stress. GSH has two redox forms: reduced GSH and glutathione disulfide (GSSG, the oxidized form) [117]. Cells can excrete GSSG or restore it to GSH through the action of GSH reductase. De novo synthesis of GSH from its amino-acid constituents-a process that involves two enzymatic steps catalyzed by glutamate cysteine ligase and GSH synthetase- [118] is essential for the adaptive elevation of GSH during oxidative stress [117]. The rate-limiting step in the de novo synthesis of GSH occurs at the cellular level of the amino acid cysteine [119]. Additionally, reduction of cystine to cysteine is an important mechanism for intracellular GSH elevation in vivo in lungs [120]. During oxidative stress and inflammation, synthesis of GSH is upregulated, possibly providing a protective or adaptive response to subsequent oxidative and inflammatory stress. An imbalance of antioxidant 
\begin{tabular}{ll} 
Table 4 Summary of selected literature relevant to intermediate energy metabolism in all-cause mortality prediction \\
\hline First author,
\end{tabular}

year, reference

Marker Study type

Study population

Key findings

Limitations

Ramakrishna et al., 2012

Lactate Single-center, observational prospective

233 Malawian children with

- The odds ratio for in-hospital mortality

(25 deaths) in children with lactate

- Single-center

$>2 \mathrm{mmol} / \mathrm{L}$ was 7.48 (95\% Cl 1.72-32.6)

study

lactate $<2 \mathrm{mmol} / \mathrm{L}$

- Low statistical

power (only 25 deaths)

Chen et al., 2015, [108] Lactate Single-center, observational prospective

1,641 patients with pneumonia cohort-study (28-day follow-up)

(861 inpatients, 780 outpatients)

(Emergency Department of Beijing

Non-survivors had higher lactate and

CURB-65 scores compared with survivors

$(p<0.001)$

- Single-center

study

Lactate predicted 28-day mortality better

- No information than CURB-65 score (AUC 0.823 vs. 0.692; $p<0.01$ )

microorganisms

Combination of lactate and CURB-65 score

improved the predictive value of CURB-65 score alone (AUC 0.851)

AUC area under the receiver operating characteristic curve $C$ confidence interval, CURB-65 score new-onset confusion urea $>7 \mathrm{mmol} / \mathrm{L}$, respiratory rate $\geq 30$ breaths per minute, systolic or diastolic blood pressure

$<90 \mathrm{mmHg}$ or $\leq 60 \mathrm{mmHg}$, respectively, age $\geq 65$ years (pneumonia/LRTI risk scoring system), $p$ p-value are statistically significant at $p<0.05$ 
Table 5 Summary of selected literature relevant to monosaccharides in all-cause mortality prediction

\begin{tabular}{|c|c|c|c|c|c|}
\hline $\begin{array}{l}\text { First author, } \\
\text { year, reference }\end{array}$ & Marker & Study type & Study population & Key findings & Limitations \\
\hline \multirow[t]{3}{*}{$\begin{array}{l}\text { Foltran et al., } \\
\text { 2013, [112] }\end{array}$} & \multirow[t]{3}{*}{ Glucose } & \multirow[t]{3}{*}{ Single-center, retrospective case-control study } & \multirow{3}{*}{$\begin{array}{l}1,018 \text { Italian non- } \\
\text { intensive care } \\
\text { patients with } \\
\text { pneumonia }\end{array}$} & \multirow[t]{2}{*}{$\begin{array}{l}\text { - Plasma glucose levels of mean } 86 \mathrm{mg} / \mathrm{dl}(95 \% \mathrm{Cl}, 61-102 \mathrm{mg} / \mathrm{dl}) \text { were } \\
\text { associated with minimal risk of in-hospital mortality }\end{array}$} & $\begin{array}{l}\text { - Only admission } \\
\text { glucose levels }\end{array}$ \\
\hline & & & & & - Single-center study \\
\hline & & & & $\begin{array}{l}\text { - The OR was } 1.33 \text { (95\% Cl 1.07-1.66) for each } 10 \mathrm{mg} / \mathrm{dl} \text { of increase in } \\
\text { plasma glucose in hyperglycemic patients (>86 mg/dl) }\end{array}$ & $\begin{array}{l}\text { - No information on } \\
\text { important confounders } \\
\text { (e.g. diabetes) }\end{array}$ \\
\hline \multirow{3}{*}{$\begin{array}{l}\text { McAlister } \\
\text { et al., 2005, } \\
{[113]}\end{array}$} & \multirow[t]{3}{*}{ Glucose } & \multirow{3}{*}{$\begin{array}{l}\text { Multicenter, observational prospective cohort } \\
\text { study (median length of in-hospital stay was } \\
6 \text { days, follow-up until hospital discharge) }\end{array}$} & \multirow[t]{3}{*}{$\begin{array}{l}\text { 2,471 Canadian } \\
\text { adults with CAP }\end{array}$} & \multirow{2}{*}{$\begin{array}{l}\text { - Patients with an admission glucose level }>11 \mathrm{mmol} / / \mathrm{l} \text { had an increased } \\
\text { risk of death }(13 \mathrm{vs} .9 \%, p=0.03) \text { and in-hospital complications }(29 \mathrm{vs} \text {. } \\
22 \%, p=0.01) \text { compared to those with glucose levels }<11 \mathrm{mmol} / \mathrm{l}\end{array}$} & $\begin{array}{l}\text { - Glucose only } \\
\text { measured once }\end{array}$ \\
\hline & & & & & $\begin{array}{l}\text { - No examination of } \\
\text { antiglycemic } \\
\text { treatments }\end{array}$ \\
\hline & & & & $\begin{array}{l}\text { - Patients with admission glucose }>11 \mathrm{mmol} / \mathrm{l} \text { had } 73 \% \text { higher mortality } \\
(95 \% \mathrm{Cl} 12-108 \%) \text { and a } 52 \% \text { higher }(12-108 \%) \text { risk of in-hospital } \\
\text { complications compared to patients with glucose levels } \leq 6.1 \mathrm{mmol} / \mathrm{l}\end{array}$ & $\begin{array}{l}\text { - Not measured long- } \\
\text { term glucose }(\mathrm{HbA} 1 \mathrm{c})\end{array}$ \\
\hline \multirow[t]{4}{*}{$\begin{array}{l}\text { Lepper et al., } \\
\text { 2012, [114] }\end{array}$} & \multirow[t]{4}{*}{ Glucose } & \multirow[t]{4}{*}{$\begin{array}{l}\text { Multicenter, prospective cohort study (6-month } \\
\text { follow-up) }\end{array}$} & \multirow[t]{4}{*}{$\begin{array}{l}\text { 6,891 German } \\
\text { patients with CAP } \\
\text { (CAPNETZ Study) }\end{array}$} & $\begin{array}{l}\text { - In patients with no pre-existing diabetes an increased serum glucose } \\
\text { level was a predictor of death at } 28 \text { and } 90 \text { days }\end{array}$ & $\begin{array}{l}\text { - Treatment of } \\
\text { pneumonia was left to } \\
\text { the discretion of the } \\
\text { doctor }\end{array}$ \\
\hline & & & & \multirow{3}{*}{$\begin{array}{l}\text { - Mild hyperglycemia }(6-10.99 \mathrm{mmol} / \mathrm{l}) \\
\text { on admission was associated with an } \\
\text { increased risk of death at } 90 \text { days (HR } 1.56 \text {, } \\
95 \% \mathrm{Cl} 1.22-2.01, p<0.001) \text {, and this risk } \\
\text { increased to } 2.37 \text { ( } 95 \% \mathrm{Cl}, 1.62-3.46 \text {, } \\
p<0.001 \text { ) when serum glucose levels } \\
\text { were } \geq 14 \mathrm{mmol} / \mathrm{l}\end{array}$} & $\begin{array}{l}\text { - Did not examine } \\
\text { changes in serum } \\
\text { glucose }\end{array}$ \\
\hline & & & & & $\begin{array}{l}\text { - Glucocorticoid } \\
\text { treatments were not } \\
\text { recorded }\end{array}$ \\
\hline & & & & & - No HbA1c tests \\
\hline
\end{tabular}

statistically significant at $p<0.05$ 
and proinflammatory genes can lead to chronic inflammation [117].

Homocysteine is built from the breakdown of the essential amino acid methionine and can subsequently be converted to cystathionine with vitamin B6 and further to cysteine. Conversely, vitamin B12 promotes remethylation of homocysteine to methionine [121, 122]. The latter reaction is catalyzed by the enzyme methionine synthase, requiring 5-methyltetrahydrofolate, the main circulating form of folate, and vitamin B12 in its cofactor form methylcobalamin [122].

Current research (Table 6) Table 6 outlines a clinical study that ascertained the status of glutathione-reflected by the reduced ratio of glutathione (GSH) to total glutathione in whole blood-as an independent mid-term predictor of all-cause mortality in post-ICU patients, whereas the total concentration of glutathione as well as the concentration of GSH alone revealed no association with 6-month mortality [118]. Although total glutathione and GSH concentrations in ICU patients have been observed as low, the quartile with the highest redox ratio of glutathione (GSH/total glutathione) carries the highest post-ICU all-cause mortality risk [118]. Lower levels of glutathione-S-bimane (GSB) - that is, intracellular GSH measured by fluorescence-activated cell sorter (FACS) - in CD4 T cells are prominent long-term mortality predictors in HIV-infected individuals, independent of CD4 T cell count [123].

Several clinical studies have demonstrated that elevated levels of plasma homocysteine independently predict long-term all-cause mortality in the elderly [124-127] as well as in younger adults $[128,129]$. In contrast, in patients after ischemic stroke a marked association is evident between high plasma homocysteine and overall mortality only after exclusion of patients with dissection [129]. Another study showed a correlation between higher homocysteine levels and increased long-term mortality in the subgroup of patients with malnutrition and inflammation [130]. Additionally, elevated plasma homocysteine levels are discernibly related to a higher death rate only in older women [126]. Besides their relation to all-cause mortality, high homocysteine concentrations are independently associated with cardiovascular mortality [128].

\section{Glycerophospholipids}

Pathway and physiological role Glycerophospholipids are glycerol-based phospholipids that form the bilayer in biological membranes. Their basic structure is composed of glycerol, to which a phosphoric acid and two fatty acids are attached as esters. An additional alcohol group (e.g., serine, choline, ethanolamine or inositol) attached to the phosphate allows the formation of distinct phosphoglycerides. The five classes of glycerophospholipids are phosphatidylcholine (PC, lecithin), phosphatidylethanolamine (PE), phosphatidylserine (PS), phosphatidylinositol (PI) and diphosphatidylgylcerol (cardiolipin) [131].

Current research (Table 7) In lipid profiling of patients undergoing coronary angiography, $19 \mathrm{PC}$ and 3 lysophosphatidylcholine (lysoPC) species reveal a noticeable association with mortality due to total and coronary artery disease. Ten of 19 PC and all 3 analyzed lysoPC species are inversely associated with mortality, whereas PC 32:0 reveals the strongest positive correlation with mortality [132]. Four lysoPC species-C16:0, C18:0, C18:1, and C18:2-account for over $90 \%$ of total plasma lysoPC concentration. The levels of these main lysoPC species as well as total lysoPC concentrations are markedly reduced in sepsis, including pulmonary infections, compared to healthy controls (Table 7). Moreover, 30-day non-survivors show higher ratios of lysoPC/PC compared with survivors [133].

\section{Sphingolipids}

Pathway and physiological role Sphingolipids are essential components of cell membranes, and in neural tissue they are important in signal transduction and cell recognition. Fundamental building blocks of sphingolipids are long-chain bases (sphingoid bases). Their amine group is linked to an acyl group (e.g., fatty acid) and the backbone of the sphingoid base is linked with phosphate to an alcohol group (serine, ethanolamine or choline). The 3 principal forms of sphingolipids are ceramide and its derivatives sphingomyelin (SM) and glycosphingolipids [134].

Current research (Table 7) Elevated plasma SM levels are an independent risk factor for CHD and an outcome predictor in patients with acute coronary syndrome [135, 136]. In lipid profiling of patients undergoing coronary angiography, 9 SM species are significantly associated with total and CHD long-term mortality (Table 7). Of 9 SM species, 5 showed an inverse association and 4 (specifically SM 16:0, 16:1, 24:1, and 24:2) displayed a positive association with total and cardiovascular mortality [132].

\section{Acylcarnitines}

Pathway and physiological role Carnitine (3-Hydroxy4- $\mathrm{N}$-trimethylammoniobutanoate) is biosynthesized in the liver and kidneys from the amino acids lysine and methionine. Nutrition is an important, but not essential, source of carnitine. The highest concentrations of carnitine are found in red meat, but carnitine is also found in other foods such as nuts, seeds, legumes, vegetables, fruits and cereals. Fatty acid oxidation and thus fatty acid energy metabolism occur in the cellular mitochondria. In the cytosol, free fatty acids are attached with a 
Table 6 Summary of selected literature relevant to oxidative status in all-cause mortality prediction

Study population Key findings

Limitations

\begin{tabular}{lll}
\hline $\begin{array}{ll}\text { First author, } \\
\text { year, reference }\end{array}$ & Marker & Study type \\
\hline Rodas et al., & - Total & Single-center, prospective observational \\
2012, [118] & glutathione & cohort study (6-month follow-up) \\
& - GSH \\
& \\
& - Glutathione \\
& redox status \\
& (GSH/total \\
& glutathione \\
& ratio)
\end{tabular}

174 patients

admitted to the

ICU (without

thoracic,

neurosurgery and

$(>17$ years of age $)$

(c)

- After division of patients

into quartiles according to

total concentration of

whole blood, no relationship

to mortality was observed

(data not shown); division of

patients into quartiles

according to GSH/total

glutathione ratio showed a

significant higher 6-month-

quartile with the highest

ratio compared to the lower

three quartiles $(p=0.026)$;

the AUC of GSH/total

glutathione ratio regarding

all-cause mortality predictio

was $0.56(p=0.18)$ with an

optimal cut-off for the GSH/

total glutathione ratio of

0.66; a stepwise multiple

logistic regression analysis

regarding 6-month-mortality

prediction showed an OR of

2.35 (Cl 1.02-5.41; $p<0.001)$

for the GSH/total glutathione

ratio

Herzenberg - Total Single-center, prospective observationa et al., 1997, glutathione cohort-study (2-3-year follow-up)
204 HIV-infected - Logistic regression analyses demonstrated

patients, who

were screened for

enrollment into

clinical trial de-

signed to deter-

mine whether

orally NAC replen-

ishes GSH in sub-

jects with low

GSH levels; how-

ever, subjects

who were finally

enrolled in the

NAC trial were

not included in

the present ob-

servational cohort

study an association between increased baseline GSB

and improved 2-3-year survival, whereas baseline

GSB levels below normal values showed a highe mortality $(p<0.0001)$

- Kaplan-Meier survival curves demonstrated that patients with baseline GSB levels below 1.05 show a significantly increased 2-3-year all-cause mortality compared to subjects with higher baseline GSB levels $(p=0.005)$; the above named optimal treshold of 1.05 for separating survivors from non-survivors was determined using ROC analyses for 2-3-year survival

- In proportional hazard analyses with inclusion of GSB levels as well as CD4 T cell counts in the model, GSB has still been demonstrated to be a significant, independent mortality predictor (RR 1.6 [95 \% Cl

$1.1-2.5], p=0.009$ ), despite its significant correlation with CD4 T cell counts $(p<0.0001)$
The study only represented the group actually studied, namely patients $>17$ years of age admitted to the ICU

Observational studies allow no statement about causal association

- Redox status of glutathione in

plasma might not be representative

for the intracellular status (Nevertheless, the plasma ratio of $\mathrm{GSH} /$ total

glutathione could be useful as a

biomarker to predict post-ICU

mortality)

- Selection bias due to exclusion of patients who finally were trial subjects of the NAC interventional trial

- No data about plasma glutathione 
Table 6 Summary of selected literature relevant to oxidative status in all-cause mortality prediction (Continued)

\section{Xiu et al.,}

2012, [124]

Wong et al

2013, [125] cohort study (follow-up of $5.1+/-1.3$ years)

Swart et al.,
2011, [126]

Homocysteine Sub-study of a prospective observational population-based cohort study (11-year follow-up)

Drewes et al., Homocysteine Post-hoc subanalysis of the 2014, [127] double-blind, randomized placebo-controlled study, stratified by plasma homocysteine levels (mean follow-up of 3.2 years)

Waskiewicz et Homocysteine Prospective observational, population-based al., 2012, [128] cohort study (mean follow-up of 5.4 years)
1,117

independently living elderly (mean age $=$ 75.1 years), selected from the Longitudinal Aging Study Aging Study
Amsterdam (LASA)

3,522 subjects with history of or risk factors for CVD (aged 7082), selected from the primary care setting in two of the three

PROSPER study sites (Netherlands and Scotland)

7,165 Polish people aged 2074 years

- In a model adjusted for sociodemographic, behavioral, and nutritional variables, plasma

homocysteine levels $>14.5 \mathrm{umol} / /$ were associated

with significantly higher mortality compared to

those $<9.3 \mathrm{umol} / \mathrm{l}$ (HR 1.8, $95 \% \mathrm{Cl} 1.20-2.71 ; p=0.002)$

- After adjustment for frailty, age, education, living circumstances, smoking, cardiovascular disease, cardiovascular risk factors and renal function, high total plasma homocysteine levels ( $\geq 15$ umol/l) were a significant all-cause mortality predictor (HR 1.25, $95 \%$ Cl 1.06-1.48, $p<0.05$ )

- After adjustment for severat confounders, women in the third and the fourth quartile of plasma homocysteine levels were associated with a significantly higher all-cause mortality risk compared to those in the first quartile

(Q3 HR 1.70, 95 \% Cl 1.08-2.65; Q4 HR 1.91, 95 \% Cl 1.22-3.00), independently of vitamin B12 status; in men there was no significant difference in

all-cause mortality rates between different quartiles of homocysteine levels in adjusted models

- In the placebo group subjects with

plasma homocysteine levels in the highest tertile showed a significantly higher all-cause mortality risk (HR 1.7, $95 \% \mathrm{Cl} 1.2-2.5, p=0.003$ ) as well as a greater risk of fatal and nonfatal CHD (HR 1.8, $95 \% \mathrm{Cl} 1.2-2.5, p=0.001)$ compared to those with low plasma homocysteine levels

- Regarding all-cause mortality the pravastatin treatment group showed an absolute risk reduction of $4.6 \%$ (95\% Cl 0.78-8.4\%) in the subgroup with high homocysteine levels compared to $-0.66 \%(95 \%$ $\mathrm{Cl}-4.0-2.7)$ in the subgroup with low homocysteine levels (absolute risk reduction difference of $5.2 \%$ $95 \%$ Cl 0.19-10.3; $p=0.04$ )

- In multivariable proportional hazards

models adjusted for sex, age and cardiovascular risk factors, RR of all-cause long-term mortality was significantly higher in plasma homocysteine
Although adjustment for several known associations with homocysteine status has been undertaken, residual confounding is still possible

Self-selection of study participants might have biased the findings toward ower homocysteine, lower age and fewer

comorbidities compared to the non-respondents,

which limits generalizability of study results and might have moved the results with underestimation of associations

Possible underestimation of the actua relationship between homocysteine levels and mortality due to selection bias, since excluded subjects were older, more likely to be cognitively impared, less physically active and had suffered CVD more often at baseline

- Study not originally designed to collect blood samples for plasma

homocysteine level assessment, which is why data could only be used from two of the three PROSPER study sites

- Some blood samples have possibly been stored at room temperature for up to $8 \mathrm{~h}$, which could have contributed to artificially high plasma homocysteine levels, and thus misclassification

No data about the intakte of vitamin B, which may lower homocysteine levels

- The immunoenzymatic method used to determine homocysteine levels in this study has shown the lowest precision of measurements in 
Table 6 Summary of selected literature relevant to oxidative status in all-cause mortality prediction (Continued)

\begin{tabular}{|c|c|c|c|c|c|}
\hline & & & & $\begin{array}{l}\text { levels }>10.51 \mathrm{umol} / \mathrm{I} \text { compared to those }<8.20 \mathrm{umol} / \mathrm{I} \\
\text { (HR 1.766, } 95 \% \mathrm{Cl} 1.197-2.605)\end{array}$ & $\begin{array}{l}\text { comparative analyses of various } \\
\text { homocysteine assay methods }\end{array}$ \\
\hline & & & & $\begin{array}{l}\text { - In Kaplan-Meier survival curves patients with } \\
\text { homocysteine concentrations in the highest } \\
\text { tercile }(>10.51 \text { umol/l) showed significantly } \\
\text { increased long-term all-cause mortality compared } \\
\text { to subjects with homocysteine levels in the lowest } \\
\text { tercile }(p=0.0003)\end{array}$ & $\begin{array}{l}\text { - Impossible to perform analyses of } \\
\text { mortality related to stroke and } \\
\text { ischemic heart disease due to low } \\
\text { number of deaths in these groups }\end{array}$ \\
\hline \multirow{3}{*}{$\begin{array}{l}\text { Naess et al., } \\
\text { 2013, [129] }\end{array}$} & \multirow{3}{*}{ Homocysteine } & \multirow{3}{*}{$\begin{array}{l}\text { Prospective, observational population-based } \\
\text { cohort study (mean follow-up of } 12.4 \text { years) }\end{array}$} & \multirow{3}{*}{$\begin{array}{l}198 \text { patients with } \\
\text { first ischemic } \\
\text { stroke living in } \\
\text { Hordaland } \\
\text { County (mean } \\
\text { age of } 47.8 \text { years) }\end{array}$} & \multirow{3}{*}{$\begin{array}{l}\text { - After adjustment for age, sex and CRP levels, } \\
\text { Cox regression analysis - excluding patients } \\
\text { with stroke caused by dissection - showed high } \\
\text { plasma homocysteine levels ( }>9 \text { ug/l) to be } \\
\text { significantly and independently associated with } \\
\text { all-cause mortality (HR 1.04, } p=0.02 \text { ) }\end{array}$} & - Small sample size \\
\hline & & & & & $\begin{array}{l}\text { - Possible selection bias due to } \\
\text { retrospective patient recruitment }\end{array}$ \\
\hline & & & & & $\begin{array}{l}\text { - High plasma homocysteine levels } \\
\text { have been shown to be significant } \\
\text { all-cause mortality predictors only after } \\
\text { exclusion of patients with dissection, } \\
\text { suggesting homocysteine to be a } \\
\text { potential confounder in mortality } \\
\text { prediction }\end{array}$ \\
\hline $\begin{array}{l}\text { Vieira et al., } \\
\text { 2010, [130] }\end{array}$ & Homocysteine & $\begin{array}{l}\text { Single-center, prospective observational } \\
\text { cohort-study ( } 2 \text {-year follow-up) }\end{array}$ & $\begin{array}{l}95 \text { predialysis } \\
\text { patients with } \\
\text { chronic kidney } \\
\text { disease (mean } \\
\text { age of } 69.4 \text { years) }\end{array}$ & $\begin{array}{l}\text { - Kaplan-Meier survival curves demonstrated a } \\
\text { significant lower survival in patients with total } \\
\text { plasma homocysteine levels and nutritional } \\
\text { status assessment (by mSGA) above the mean } \\
\text { level compared to lower levels ( } p=0.04 \text {; survival } \\
\text { at } 24 \text { months }=50 \% \text { ) }\end{array}$ & - Small sample size \\
\hline \multirow[t]{2}{*}{$\begin{array}{l}\text { Tekin et al., } \\
\text { 2012, [144] }\end{array}$} & \multirow[t]{2}{*}{ Homocysteine } & \multirow[t]{2}{*}{$\begin{array}{l}\text { Single-center, prospective observational } \\
\text { cohort-study (1-year follow-up) }\end{array}$} & \multirow{2}{*}{$\begin{array}{l}70 \text { patients with } \\
\mathrm{HF} \text { (left ventricle } \\
\text { ejection fractions } \\
<35 \%) \text { (mean } \\
\text { age } 60+/-12 \text { ) }\end{array}$} & $\begin{array}{l}\text { - Serum homocysteine levels were significantly } \\
\text { higher in non-survivors compared with survivors } \\
(20.8+/-5.8 \text { vs. } 16.9+/-5.1 \text { umol//, } p=0.029)\end{array}$ & \multirow[t]{2}{*}{ - Small sample size } \\
\hline & & & & $\begin{array}{l}\text { - With an optimal cut-off value of }>17.45 \text { umol//, } \\
\text { the AUC of serum homocysteine levels with regard } \\
\text { to mid-term mortality prediction was } 0.855(95 \% \mathrm{Cl} \\
0.792-0.965, p<0.001)\end{array}$ & \\
\hline
\end{tabular}

levels $>10.51 \mathrm{umol} / \mathrm{l}$ compared to those $<820 \mathrm{umol} /$

- n Kaplan-Meier survival curves patients with 作 tercile $(p=0.0003)$ Cox regression analysis - excluding patients with stroke caused by dissection - showed high plasma homocysteine levels (>9 ug/) to be significantly and indepe

AUC area under the receiver operating characteristic curve, $C I$ confidence interval, $C H D$ coronary heart disease, CKD chronic kidney disease, CRP C-reactive protein, CVD cardiovascular disease, GSB glutathione-Sbimane, GSH glutathione, HF heart failure, HIMS Health in Men Study, HIV human immunodeficiency virus, HR hazard ratio, ICU intensive care unit, LASA Longitudinal Aging Study Amsterdam, mSGA modified Subjective Global Nutritional Assessment, NAC N-acetylcysteine, NAHSIT Nutrition and Health Survey in Taiwan, OR odds ratio, $p$-value are statistically significant at $p<0.05$, PROSPER PROspective Study of Pravastatin in the Elderly at Risk, $Q$ quartile, $R O C$ receiver operationg characteristic, $R R$ relative risk 
Table 7 Summary of selected literature relevant to sphingolipids and glycerophospholipids in all-cause mortality prediction

\begin{tabular}{|c|c|c|c|}
\hline $\begin{array}{l}\text { First author, year, } \\
\text { reference }\end{array}$ & Marker & Study type & Study population \\
\hline \multirow{3}{*}{$\begin{array}{l}\text { Sigruener et al., } \\
\text { 2014, [132] }\end{array}$} & - Sphingomyelin & \multirow{3}{*}{$\begin{array}{l}\text { Single-center, prospective } \\
\text { observational cohort-study } \\
\text { (median follow-up of } 8 \text { year) }\end{array}$} & \multirow{3}{*}{$\begin{array}{l}2583 \text { CAD-positve patients and } 733 \\
\text { controls (LURIC Study) }\end{array}$} \\
\hline & $\begin{array}{l}\text { - Phosphatidyl- } \\
\text { choline }\end{array}$ & & \\
\hline & $\begin{array}{l}\text { - Lysophosphati- } \\
\text { dylcholine }\end{array}$ & & \\
\hline
\end{tabular}

Key findings

Limitations

Drobnik et al., Lysophosphatidyl- Single-center, prospective 2003, [133] choline observational cohort-study (30-day follow-up)

102 patients with sepsis admitted to the University Hospital of Regensburg (Germany) and 56 healthy controls

-9 PC species (PC 30:0, 30:1, 32:0, 32:1, 34:1,
34:2, 36:1, 38:0, 38:2) were positively associa

$34: 2,36: 1,38: 0,38: 2)$ were positively associated with mortality

PC 32:0 revealed the strongest positive association with mortality

- 10 PC species (PC 38:3-38:7, 36:4, 36:5, 40:6, 40:7) were significantly associated with a protective effect

- LysoPC 16:0, 18:0, and 18:2 were all associated with a protective effect

- The 4 SM species 16:0, 16:1, 24:1, and 24:2 showed positive association with mortality

- All 12 different lysoPC species and lysoPC-PC ratios were markedly decreased in patients with sepsis compared with healty controls

- The 4 lysoPC species, C16:0, C:18:0, C18:1, and C18:2, accounted for over $90 \%$ of total lysoPC concentration $\begin{array}{ll}\text { Schlitt et al., } \quad \text { Sphingomyelin } & \begin{array}{l}\text { Multicenter, prospective } \\ \text { observational cohort-study }\end{array}\end{array}$ 2006, [135] (median follow-up of 6 year)

1102 patients with CAD and 444 healthy controls

CAD patients showed higher plasma SM levels than healthy controls (mean 51.8 vs. $44.9 \mathrm{mg} / \mathrm{dl} ; p<0.001$ )

- In multivariate analysis, elevated SM (>48.1 mg/dl) was related to cardiovascular death or nonfatal myocardial infarction (HR 1.8, $95 \% \mathrm{Cl} 1.0-3.3, p<0.05)$ in patients with ACS
556 patients scheduled for coronary angiography in New York
- Patients with CAD had higher plasma SM concentrations compared with non-CAD patients (median 52 vs. 44 mg/dl, $p<0.0001)$

- The odds ratios for CAD patients for the third $(2.83,95 \% \mathrm{C}$ $1.74-4.60, p<0.0001)$ and fourth $(2.59,95 \%$ CI 1.60-4.19,

$p=0.0001)$ quartiles were higher than the first quartile
- Single-center study

- Small patient populations

No information about causes of sepsis

- Only two-center study

No autopsy performed

Only two-center study No prospective design

ACS acute coronary syndrome, CAD coronary artery disease, CI confidence interval, HR hazard ratio, LURIC Ludwigshafen Risk and Cardiovascular Health study, Germany, lysoPC lysophosphatidylcholine, OR odds ratio, $p$ p-value are statistically significant at $p<0.05, P C$ phosphatidylcholine, $S M$ sphingomyelin 
Table 8 Summary of selected literature relevant to acylcarnitines in all-cause mortality prediction

\begin{tabular}{|c|c|c|c|c|c|}
\hline $\begin{array}{l}\text { First author, } \\
\text { year, reference }\end{array}$ & Marker & Study type & Study population & Key findings & Limitations \\
\hline \multirow[t]{3}{*}{$\begin{array}{l}\text { Kalim et al., } \\
\text { 2013, [138] }\end{array}$} & \multirow[t]{3}{*}{ Oleoylcarnitine } & \multirow{3}{*}{$\begin{array}{l}2 \text { independent, } \\
\text { observational case- } \\
\text { control studies } \\
\text { (ArMORR Study) }\end{array}$} & \multirow{2}{*}{$\begin{array}{l}\text { I: } 100 \text { non-survivors of } 1 \text {-year } \\
\mathrm{HD} \text { and } 100 \text { survivors of at least } \\
1 \text {-year HD matched for age, sex, } \\
\text { and race }\end{array}$} & \multirow{2}{*}{$\begin{array}{l}\text { I: Oleoylcarnitine showed the } \\
\text { strongest association with } \\
\text { cardiovascular mortality after } \\
\text { multivariable adjustment (OR } \\
\text { ratio per SD } 2.3,95 \% \mathrm{Cl} 1.4-3.8 \text {, } \\
p=0.001 \text { ) }\end{array}$} & $\begin{array}{l}\text { - Measurement of basline } \\
\text { metabolites after } \\
\text { starting hemodialysis }\end{array}$ \\
\hline & & & & & \multirow{2}{*}{$\begin{array}{l}\text { - Accuracy of ICD-9 codes } \\
\text { for cardiac diagnoses } \\
\text { not completely sensitive } \\
\text { or specific }\end{array}$} \\
\hline & & & $\begin{array}{l}\text { I: } 100 \text { non-survivors of } 1 \text {-year } \\
\text { HD and } 200 \text { survivors of at least } \\
1 \text { year HD }\end{array}$ & $\begin{array}{l}\text { II: Oleoylcarnitine was } \\
\text { associated with cardiovascular } \\
\text { death (OR per SD 1.4, } 95 \% \mathrm{Cl} \\
1.1-1.9, p=0.008 \text { ) }\end{array}$ & \\
\hline
\end{tabular}

ArMORR The Accelerated Mortality on Renal Replacement Study, United States, Cl confidence interval, HD hemodialysis, ICD-9 International Classification of Diseases, $O R$ odds ratio, $p$ p-value are statistically significant at $p<0.05$; $S D$, standard deviation

thioester bond to coenzyme A (CoA). Carnitine transports long-chain acyl groups of fatty acids from the cellular cytosol through the mitochondrial membrane. On the outer mitochondrial membrane, carnitine acyltransferase 1 transfers acyl-CoA to the hydroxyl group of carnitine, resulting in acylcarnitine. The enzyme carnitineacylcarnitine translocase catalyzes the transport of acylcarnitine to the inner mitochondrial membrane where carnitine acyltransferase II re-converts acylcarnitine to acyl-CoA [137].

Current research (Table8) Metabolic profiling of 165 polar metabolites was performed in hemodialysis patients. Individuals who died of a cardiovascular cause within 1 year of initiating hemodialysis revealed markedly higher concentrations of the 4 long-chain acylcarnitines oleoylcarnitine, linoleylcarnitine, palmitoylcarnitine, and stearoylcarnitine compared with survivors who had undergone hemodialysis for 1 year. Of these metabolites, oleoylcarnitine showed the strongest association with cardiovascular mortality after multivariable adjustment (Table 8) [138].

\section{Conclusions}

Since many uncertainties remain in predicting all-cause mortality in patients hospitalized for CAP or for exacerbated COPD, additional prospective and retrospective observational studies are needed to ascertain other potential contributors to all-cause mortality in order to improve the prediction of initial high risk. Metabolomic analysis using MS may facilitate identification of outcome-specific metabolite signatures that could potentially generate new metabolic biomarkers of various organic systems as all-cause mortality predictors in CAP and in exacerbated COPD. Improvement in early and accurate identification of high-risk patients can help optimize short- and long-term management strategies in LRTI and as a result, potentially improve survival, leading to a more cost-effective allocation of medical

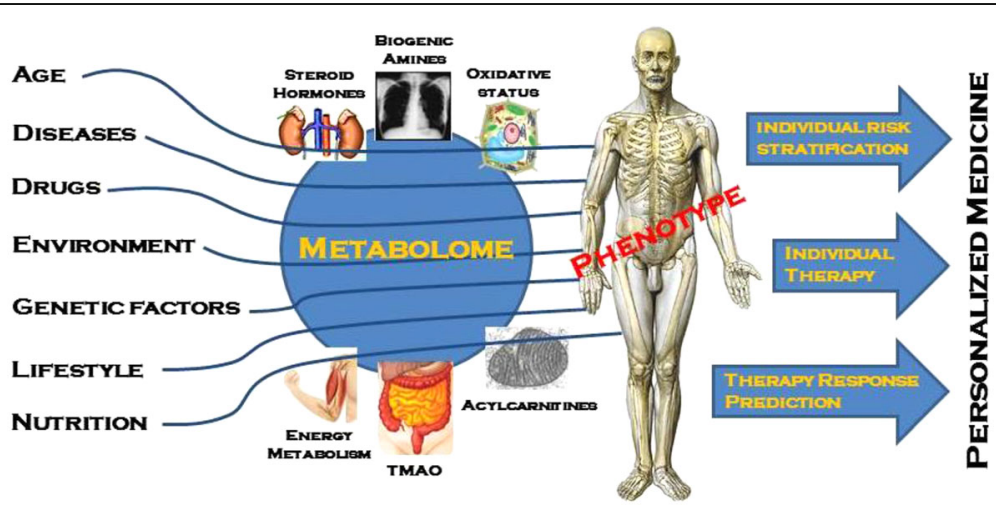

Fig. 2 Metabolomics to improve outcome prediction in LRTI. Figure 2 shows the influence of different factors such as age, diseases, drugs, environment, genetic factors, lifestyle and nutrition on endogenous metabolome which defines the human phenotype. The knowledge of metabolic interactions may provide individual risk stratification, prediction of therapy response as well as new targets for future individual therapy and therefore a form of personalized medicine. (Abbr.: TMAO, trimethylamine-N-oxide) 
resources. In addition, deeper knowledge of metabolic interactions in LRTI may provide new targets for future individual therapy and also be beneficial in predicting responses to therapy.

\section{Abbreviations}

ACTH: Adrenocorticotropic hormone; ADMA: Asymmetric dimethylarginine; AKI: Acute kidney injury; Arg: L-arginine; AUC (or AUROC): Area under the receiver operating characteristic curve; BODE: Body mass index, airflow obstruction, dyspnea and exercise capacity index; CAP: Community-acquired pneumonia; CE: Capillary electrophoresis; CHD: Coronary heart disease; Cl: Confidence interval; CKD: Chronic kidney disease; CoA: Coenzyme A; COPD: Chronic obstructive pulmonary disease; CRP: C-reactive protein; CURB65: New-onset confusion, urea $>7 \mathrm{mmol} / \mathrm{L}$, respiratory rate $\geq 30$ breaths $/ \mathrm{min}$, systolic or diastolic blood pressure $<90 \mathrm{mmHg}$ or $\leq 60 \mathrm{mmHg}$, respectively, age $\geq 65$ years (pneumonia/LRTI risk scoring system); CVD: Cardiovascular disease; DHEA: Dehydroepiandrosterone; DHEA-S: Dehydroepiandrosteronesulfate; DHT: Dihydrotestosterone; EGFR: Estimated glomerular filtration rate; GC: Gas chromatography; GSB: Glutathione-S-bimane; GSH: Glutathione; FACS: Fluorescence-activated cell sorter; FC: Free cortisol; FT: Free testosterone; HD: Hemodialysis; HR: Hazard ratio; ICU: Intensive care unit; IDO: Indoleamine-2,3-dioxygenase; Kyn: Kynurenine; LC: Liquid chromatography; LRTI: Lower respiratory tract infection; IysoPC: Lysophosphatidylcholine; MS: Mass spectrometry; NO: Nitric oxide; NOS: Nitric oxide synthases; NT: Nitrotyrosine; NT-proBNP: Pro-B-type natriuretic peptide; OR: Odds ratio; PC: Phosphatidylcholine; PCT: Procalcitonin; PF: PaO2/FiO2; ProADM: Proadrenomedullin; PSI: Pneumonia severity index; RNS: Reactive nitrogen species; ROC: Receiver operating characteristics; ROS: Reactive oxygen species; SDMA: Symmetric dimethylarginine; SM: Sphingomyelin; TC: Total cortisol; TT: Total testosterone; TMA: Trimethylamine; TMAO: Trimethylamine-N-oxide; Trp: Tryptophan; Tyr: Tyrosine.
\end{abstract}

\section{Competing interests}

No potential conflict of interest relevant to this systematic clinical review was reported.

\section{Author details}

Medical University Department, Division of General Internal and Emergency Medicine, Kantonsspital Aarau, Aarau, Switzerland. ${ }^{2}$ Department of Laboratory Medicine, Kantonsspital Aarau, Aarau, Switzerland. ${ }^{3}$ Principal, Medical Linguistics Consulting, North Olmsted, OH, USA. ${ }^{4}$ University Department of Medicine, Kantonsspital Aarau, Tellstrasse, CH-5001 Aarau, Switzerland.

\section{Received: 5 August 2015 Accepted: 29 September 2015}

\section{Published online: 15 October 2015}

\section{References}

1. Oliver SG, Winson MK, Kell DB, Baganz F. Systematic functional analysis of the yeast genome. Trends Biotechnol. 1998;16(9):373-8.

2. Fiehn O. Combining genomics, metabolome analysis, and biochemical modelling to understand metabolic networks. Comp Funct Genomics. 2001;2(3):155-68.

3. Wheelock CE, Goss VM, Balgoma D, Nicholas B, Brandsma J, Skipp PJ, et al. Application of 'omics technologies to biomarker discovery in inflammatory lung diseases. Eur Respir J. 2013;42(3):802-25.

4. Kaddurah-Daouk R, Kristal BS, Weinshilboum RM. Metabolomics: a global biochemical approach to drug response and disease. Annu Rev Pharmacol Toxicol. 2008;48:653-83.

5. Konig S. Urine molecular profiling distinguishes health and disease: new methods in diagnostics? Focus on UPLC-MS. Expert Rev Mol Diagn. 2011;11(4):383-91.

6. Tenori L, Oakman C, Claudino WM, Bernini P, Cappadona S, Nepi S, et al. Exploration of serum metabolomic profiles and outcomes in women with metastatic breast cancer: a pilot study. Mol Oncol. 2012;6(4):437-44.

7. Zhang A, Sun H, Dou S, Sun W, Wu X, Wang P, et al. Metabolomics study on the hepatoprotective effect of scoparone using ultra-performance liquid chromatography/electrospray ionization quadruple time-of-flight mass spectrometry. Analyst. 2013;138(1):353-61.
8. Schuetz P, Aujesky D, Muller C, Muller B. Biomarker-guided personalised emergency medicine for all - hope for another hype? Swiss Med Wkly. 2015;145:w14079.

9. Weckwerth W. Metabolomics in systems biology. Annu Rev Plant Biol. 2003;54:669-89.

10. Kutz A, Briel M, Christ-Crain M, Stolz D, Bouadma L, Wolff M, et al. Prognostic value of procalcitonin in respiratory tract infections across clinical settings. Crit Care. 2015;19(1):74.

11. Schuetz P, Mueller B. The role of immune and metabolic biomarkers for improved management of sepsis patients. Expert Rev Clin Immunol. 2014;10(9):1255-62.

12. Schuetz P, Mueller B. Biomarker-guided de-escalation of empirical therapy is associated with lower risk for adverse outcomes. Intensive Care Med. 2014;40(1):141.

13. Rast A, Mueller B, Schuetz P. Clinical scores and blood biomarkers for early risk assessment of patients presenting to the emergency department. OA Emergency Medicine. 2014;1(1):2.

14. Albrich WC, Ruegger K, Dusemund F, Schuetz P, Arici B, Litke A, et al. Biomarker-enhanced triage in respiratory infections: a proof-of-concept feasibility trial. Eur Respir J. 2013;42(4):1064-75.

15. Schuetz P, Wolbers M, Christ-Crain M, Thomann R, Falconnier C, Widmer I, et al. Prohormones for prediction of adverse medical outcome in community-acquired pneumonia and lower respiratory tract infections. Crit Care. 2010;14(3):R106.

16. Schuetz P, Raad I, Amin DN. Using procalcitonin-guided algorithms to improve antimicrobial therapy in ICU patients with respiratory infections and sepsis. Curr Opin Crit Care. 2013;19(5):453-60.

17. Schuetz P, Litke A, Albrich WC, Mueller B. Blood biomarkers for personalized treatment and patient management decisions in community-acquired pneumonia. Curr Opin Infect Dis. 2013;26(2):159-67.

18. Schuetz P, Hausfater P, Amin D, Haubitz S, Fassler L, Grolimund E, et al. Optimizing triage and hospitalization in adult general medical emergency patients: the triage project. BMC Emerg Med. 2013;13:12.

19. Kung HC, Hoyert DL, Xu J, Murphy SL. Deaths: final data for 2005. Natl Vital Stat Rep. 2008;56(10):1-120.

20. Brown PD, Lerner SA. Community-acquired pneumonia. Lancet. 1998;352(9136):1295-302.

21. File TM. Community-acquired pneumonia. Lancet. 2003;362(9400):1991-2001.

22. Schuetz P, Albrich WC, Suter I, Hug BL, Christ-Crain M, Holler T, et al. Quality of care delivered by fee-for-service and DRG hospitals in Switzerland in patients with community-acquired pneumonia. Swiss Med Wkly. 2011;141:w13228.

23. Menendez R, Torres A, Zalacain R, Aspa J, Martin Villasclaras JJ, Borderias L, et al. Risk factors of treatment failure in community acquired pneumonia: implications for disease outcome. Thorax. 2004;59(11):960-5.

24. Almirall J, Bolibar I, Vidal J, Sauca G, Coll P, Niklasson B, et al. Epidemiology of community-acquired pneumonia in adults: a population-based study. Eur Respir J. 2000;15(4):757-63.

25. Guertler C, Wirz B, Christ-Crain M, Zimmerli W, Mueller B, Schuetz P. Inflammatory responses predict long-term mortality risk in communityacquired pneumonia. Eur Respir J. 2011;37(6):1439-46.

26. Schuetz P, Suter-Widmer I, Chaudri A, Christ-Crain M, Zimmerli W, Mueller B, et al. Prognostic value of procalcitonin in community-acquired pneumonia. Eur Respir J. 2011;37(2):384-92.

27. Suter-Widmer I, Christ-Crain M, Zimmerli W, Albrich W, Mueller B, Schuetz P, et al. Predictors for length of hospital stay in patients with communityacquired pneumonia: results from a Swiss multicenter study. BMC Pulm Med. 2012;12:21.

28. Alan M, Grolimund E, Kutz A, Christ-Crain M, Thomann R, Falconnier C, et al. Clinical risk scores and blood biomarkers as predictors of long-term outcome in patients with community-acquired pneumonia: a 6-year prospective follow-up study. J Intern Med. 2014;278(2):174-84.

29. Fine MJ, Auble TE, Yealy DM, Hanusa BH, Weissfeld LA, Singer DE, et al. A prediction rule to identify low-risk patients with community-acquired pneumonia. N Engl J Med. 1997;336(4):243-50.

30. Niederman MS, Mandell LA, Anzueto A, Bass JB, Broughton WA, Campbell $G D$, et al. Guidelines for the management of adults with communityacquired pneumonia. Diagnosis, assessment of severity, antimicrobial therapy, and prevention. Am J Respir Crit Care Med. 2001;163(7):1730-54.

31. Schuetz P, Marlowe RJ, Mueller B. The prognostic blood biomarker proadrenomedullin for outcome prediction in patients with chronic 
obstructive pulmonary disease (COPD): a qualitative clinical review. Clin Chem Lab Med. 2015;53(4):521-39.

32. Grolimund E, Kutz A, Marlowe RJ, Vogeli A, Alan M, Christ-Crain M, et al. Long-term Prognosis in COPD Exacerbation: Role of Biomarkers, Clinical Variables and Exacerbation Type. COPD. 2014.

33. Schuetz P, Christ-Crain M, Morgenthaler NG, Struck J, Bergmann A, Muller B. Circulating precursor levels of endothelin-1 and adrenomedullin, two endothelium-derived, counteracting substances, in sepsis. Endothelium. 2007;14(6):345-51.

34. Huang DT, Weissfeld LA, Kellum JA, Yealy DM, Kong L, Martino M, et al. Risk prediction with procalcitonin and clinical rules in community-acquired pneumonia. Ann Emerg Med. 2008;52(1):48-58. e2.

35. Jensen JU, Heslet $L$, Jensen $T H$, Espersen $K$, Steffensen $P$, Tvede $M$. Procalcitonin increase in early identification of critically ill patients at high risk of mortality. Crit Care Med. 2006;34(10):2596-602.

36. Haeuptle J, Zaborsky R, Fiumefreddo R, Trampuz A, Steffen I, Frei R, et al. Prognostic value of procalcitonin in Legionella pneumonia. Eur J Clin Microbiol Infect Dis. 2009;28(1):55-60

37. Kruger S, Ewig S, Marre R, Papassotiriou J, Richter K, von Baum H, et al. Procalcitonin predicts patients at low risk of death from community-acquired pneumonia across all CRB-65 classes. Eur Respir J. 2008;31(2):349-55.

38. Restrepo Ml, Faverio P, Anzueto A. Long-term prognosis in communityacquired pneumonia. Curr Opin Infect Dis. 2013;26(2):151-8.

39. Kellum JA, Kong L, Fink MP, Weissfeld LA, Yealy DM, Pinsky MR, et al. Understanding the inflammatory cytokine response in pneumonia and sepsis: results of the Genetic and Inflammatory Markers of Sepsis (GenIMS) Study. Arch Intern Med. 2007;167(15):1655-63.

40. Stolz D, Kostikas K, Blasi F, Boersma W, Milenkovic B, Lacoma A, et al. Adrenomedullin refines mortality prediction by the BODE index in COPD: the "BODE-A" index. Eur Respir J. 2014:43(2):397-408.

41. Zuur-Telgen MC, Brusse-Keizer MG, Vandervalk PD, van der Palen J, Kerstjens HA, Hendrix MG. Stable state MR-proadrenomedullin level is a strong predictor for mortality in COPD patients. Chest. 2013. doi:10.1378/chest.13-1063.

42. Celli BR, Cote CG, Marin JM, Casanova C, Montes de Oca M, Mendez RA, et al. The body-mass index, airflow obstruction, dyspnea, and exercise capacity index in chronic obstructive pulmonary disease. N Engl J Med. 2004;350(10):1005-12.

43. Ghayee HK, Auchus RJ. Basic concepts and recent developments in human steroid hormone biosynthesis. Rev Endocr Metab Disord. 2007;8(4):289-300.

44. Chrousos GP. The hypothalamic-pituitary-adrenal axis and immunemediated inflammation. N Engl J Med. 1995;332(20):1351-62.

45. Nylen ES, Muller B. Endocrine changes in critical illness. J Intensive Care Med. 2004;19(2):67-82.

46. Muller B. Endocrine aspects of critical illness. Ann Endocrinol (Paris). 2007:68(4):290-8.

47. Van den Berghe $\mathrm{GH}$. Acute and prolonged critical illness are two distinct neuroendocrine paradigms. Verh K Acad Geneeskd Belg. 1998;60(6):487-518. discussion -20 .

48. Vermes I, Beishuizen A. The hypothalamic-pituitary-adrenal response to critical illness. Best Pract Res Clin Endocrinol Metab. 2001;15(4):495-511.

49. Blum CA, Mueller C, Schuetz P, Fluri F, Trummler M, Mueller B, et al Prognostic value of dehydroepiandrosterone-sulfate and other parameters of adrenal function in acute ischemic stroke. PLoS One. 2013;8(5):e63224.

50. Oberbeck R, Kobbe P. Dehydroepiandrosterone (DHEA): a steroid with multiple effects. Is there any possible option in the treatment of critical illness? Curr Med Chem. 2010;17(11):1039-47.

51. Oberbeck R, Dahlweid M, Koch R, van Griensven M, Emmendorfer A, Tscherne $\mathrm{H}$, et al. Dehydroepiandrosterone decreases mortality rate and improves cellular immune function during polymicrobial sepsis. Crit Care Med. 2001;29(2):380-4.

52. Schmitz D, Kobbe P, Wegner A, Hammes F, Oberbeck R. Dehydroepiandrosterone during sepsis: does the timing of administration influence the effectiveness. J Surg Res. 2010;163(2):e73-7.

53. Mueller C, Blum CA, Trummler M, Stolz D, Bingisser R, Mueller C, et al. Association of adrenal function and disease severity in community-acquired pneumonia. PLoS One. 2014;9(6):e99518.

54. Liarte S, Chaves-Pozo E, Abellan E, Meseguer J, Mulero V, Garcia-Ayala A. 17beta-Estradiol regulates gilthead seabream professional phagocyte responses through macrophage activation. Dev Comp Immunol. 2011;35(1):19-27.
55. Bengtsson AK, Ryan EJ, Giordano D, Magaletti DM, Clark EA. 17beta-estradiol (E2) modulates cytokine and chemokine expression in human monocytederived dendritic cells. Blood. 2004;104(5):1404-10.

56. Asai K, Hiki N, Mimura Y, Ogawa T, Unou K, Kaminishi M. Gender differences in cytokine secretion by human peripheral blood mononuclear cells: role of estrogen in modulating LPS-induced cytokine secretion in an ex vivo septic model. Shock. 2001;16(5):340-3.

57. Rahman F, Christian HC. Non-classical actions of testosterone: an update Trends Endocrinol Metab. 2007;18(10):371-8.

58. Hughes GC. Progesterone and autoimmune disease. Autoimmun Rev. 2012;11(6-7):A502-14.

59. Christ-Crain M, Stolz D, Jutla S, Couppis O, Muller C, Bingisser R, et al. Free and total cortisol levels as predictors of severity and outcome in community-acquired pneumonia. Am J Respir Crit Care Med. 2007;176(9):913-20.

60. Kolditz M, Hoffken G, Martus P, Rohde G, Schutte H, Bals R, et al. Serum cortisol predicts death and critical disease independently of CRB-65 score in community-acquired pneumonia: a prospective observational cohort study. BMC Infect Dis. 2012;12:90

61. Kolditz M, Halank M, Schulte-Hubbert B, Hoffken G. Adrenal function is related to prognosis in moderate community-acquired pneumonia. Eur Respir J. 2010;36(3):615-21.

62. Salluh JI, Bozza FA, Soares M, Verdeal JC, Castro-Faria-Neto HC, Lapa ESJR, et al. Adrenal response in severe community-acquired pneumonia: impact on outcomes and disease severity. Chest. 2008;134(5):947-54.

63. Cortes-Puch I, Hicks CW, Sun J, Solomon SB, Eichacker PQ, Sweeney DA, et al. Hypothalamic-pituitary-adrenal axis in lethal canine Staphylococcus aureus pneumonia. Am J Physiol Endocrinol Metab. 2014;307(11):E994-E1008.

64. Arlt W, Hammer F, Sanning P, Butcher SK, Lord JM, Allolio B, et al. Dissociation of serum dehydroepiandrosterone and dehydroepiandrosterone sulfate in septic shock. J Clin Endocrinol Metab. 2006;91(7):2548-54.

65. Ohlsson C, Labrie F, Barrett-Connor E, Karlsson MK, Ljunggren O, Vandenput $L$, et al. Low serum levels of dehydroepiandrosterone sulfate predict all-cause and cardiovascular mortality in elderly Swedish men. J Clin Endocrinol Metab. 2010;95(9):4406-14.

66. Hsu HJ, Yen CH, Chen CK, Hsu KH, Hsiao CC, Lee CC, et al. Low plasma DHEA-S increases mortality risk among male hemodialysis patients. Exp Gerontol. 2012;47(12):950-7.

67. Feng JY, Liu KT, Abraham E, Chen CY, Tsai PY, Chen YC, et al. Serum estradiol levels predict survival and acute kidney injury in patients with septic shock-a prospective study. PLoS One. 2014;9(6):e97967.

68. Shores MM, Biggs ML, Arnold AM, Smith NL, Longstreth Jr WT, Kizer JR, et al. Testosterone, dihydrotestosterone, and incident cardiovascular disease and mortality in the cardiovascular health study. J Clin Endocrinol Metab. 2014;99(6):2061-8

69. Friedrich N, Schneider HJ, Haring R, Nauck M, Volzke H, Kroemer HK, et al. Improved prediction of all-cause mortality by a combination of serum total testosterone and insulin-like growth factor I in adult men. Steroids. 2012;77(1-2):52-8.

70. Grossmann M, Hoermann R, Ng Tang Fui M, Zajac JD, lerino FL, Roberts MA Sex steroids levels in chronic kidney disease and kidney transplant recipients: associations with disease severity and prediction of mortality. Clin Endocrinol (Oxf). 2014;82(5):767-75.

71. Araujo AB, Kupelian V, Page ST, Handelsman DJ, Bremner WJ, McKinlay JB. Sex steroids and all-cause and cause-specific mortality in men. Arch Intern Med. 2007;167(12):1252-60.

72. de Padua MA, Silva TC, Takada JY, Avakian SD, Strunz CM, Machado Cesar $L A$, et al. Long-term prospective study of the influence of estrone levels on events in postmenopausal women with or at high risk for coronary artery disease. Scientific World Journal. 2012;2012:363595.

73. Moncada S, Higgs A. The L-arginine-nitric oxide pathway. N Engl J Med. 1993;329(27):2002-12.

74. Scott JA, North ML, Rafii M, Huang H, Pencharz P, Subbarao P, et al. Asymmetric dimethylarginine is increased in asthma. Am J Respir Crit Care Med. 2011;184(7):779-85.

75. Schwedhelm E, Boger $\mathrm{RH}$. The role of asymmetric and symmetric dimethylarginines in renal disease. Nat Rev Nephrol. 2011;7(5):275-85.

76. Scott JA, Duongh M, Young AW, Subbarao P, Gauvreau GM, Grasemann H. Asymmetric dimethylarginine in chronic obstructive pulmonary disease (ADMA in COPD). Int J Mol Sci. 2014;15(4):6062-71. 
77. Boger RH, Sullivan LM, Schwedhelm E, Wang TJ, Maas R, Benjamin EJ, et al. Plasma asymmetric dimethylarginine and incidence of cardiovascular disease and death in the community. Circulation. 2009;119(12):1592-600.

78. Pizzarelli F, Maas R, Dattolo P, Tripepi G, Michelassi S, D'Arrigo G, et al. Asymmetric dimethylarginine predicts survival in the elderly. Age (Dordr). 2013;35(6):2465-75.

79. Siegerink B, Maas R, Vossen CY, Schwedhelm E, Koenig W, Boger R, et al. Asymmetric and symmetric dimethylarginine and risk of secondary cardiovascular disease events and mortality in patients with stable coronary heart disease: the KAROLA follow-up study. Clin Res Cardiol. 2013;102(3):193-202.

80. Koch A, Weiskirchen R, Kunze J, Duckers H, Bruensing J, Buendgens L, et al. Elevated asymmetric dimethylarginine levels predict short- and long-term mortality risk in critically ill patients. J Crit Care. 2013;28(6):947-53.

81. Koch A, Weiskirchen R, Bruensing J, Duckers H, Buendgens L, Kunze J, et al. Regulation and prognostic relevance of symmetric dimethylarginine serum concentrations in critical illness and sepsis. Mediators Inflamm. 2013;2013:413826.

82. Gore MO, Luneburg N, Schwedhelm E, Ayers CR, Anderssohn M, Khera A, et al. Symmetrical dimethylarginine predicts mortality in the general population: observations from the Dallas heart study. Arterioscler Thromb Vasc Biol. 2013;33(11):2682-8.

83. Mellor AL, Munn DH. IDO expression by dendritic cells: tolerance and tryptophan catabolism. Nat Rev Immunol. 2004;4(10):762-74.

84. Hwu P, Du MX, Lapointe R, Do M, Taylor MW, Young HA. Indoleamine 2,3-dioxygenase production by human dendritic cells results in the inhibition of T cell proliferation. J Immunol. 2000;164(7):3596-9.

85. Suzuki Y, Suda T, Yokomura K, Suzuki M, Fujie M, Furuhashi K, et al. Serum activity of indoleamine 2,3-dioxygenase predicts prognosis of communityacquired pneumonia. J Infect. 2011;63(3):215-22.

86. Darcy CJ, Davis JS, Woodberry T, McNeil YR, Stephens DP, Yeo TW, et al. An observational cohort study of the kynurenine to tryptophan ratio in sepsis: association with impaired immune and microvascular function. PLoS One. 2011;6(6):e21185.

87. Huttunen R, Syrjanen J, Aittoniemi J, Oja SS, Raitala A, Laine J, et al. High activity of indoleamine 2,3 dioxygenase enzyme predicts disease severity and case fatality in bacteremic patients. Shock. 2010;33(2):149-54.

88. Macdonald J, Galley HF, Webster NR. Oxidative stress and gene expression in sepsis. Br J Anaesth. 2003;90(2):221-32.

89. Beckman JS, Koppenol WH. Nitric oxide, superoxide, and peroxynitrite: the good, the bad, and ugly. Am J Physiol. 1996;271(5 Pt 1):C1424-37.

90. Pacher P, Beckman JS, Liaudet L. Nitric oxide and peroxynitrite in health and disease. Physiol Rev. 2007;87(1):315-424

91. Jin H, Webb-Robertson BJ, Peterson ES, Tan R, Bigelow DJ, Scholand MB, et al. Smoking, COPD, and 3-nitrotyrosine levels of plasma proteins. Environ Health Perspect. 2011;119(9):1314-20.

92. Qian J, You H, Zhu Q, Ma S, Zhou Y, Zheng Y, et al. Nitrotyrosine level was associated with mortality in patients with acute kidney injury. PLoS One. 2013;8(11):e79962

93. Zeisel SH, Blusztajn JK. Choline and human nutrition. Annu Rev Nutr. 1994;14:269-96.

94. Millian NS, Garrow TA. Human betaine-homocysteine methyltransferase is a zinc metalloenzyme. Arch Biochem Biophys. 1998;356(1):93-8.

95. Finkelstein JD, Harris BJ, Kyle WE. Methionine metabolism in mammals: kinetic study of betaine-homocysteine methyltransferase. Arch Biochem Biophys. 1972;153(1):320-4.

96. Zeisel SH, Mar MH, Howe JC, Holden JM. Concentrations of choline-containing compounds and betaine in common foods. J Nutr. 2003;133(5):1302-7.

97. AI-Waiz M, Mikov M, Mitchell SC, Smith RL. The exogenous origin of trimethylamine in the mouse. Metabolism. 1992;41(2):135-6.

98. Lang DH, Yeung CK, Peter RM, Ibarra C, Gasser R, Itagaki K, et al. Isoform specificity of trimethylamine $\mathrm{N}$-oxygenation by human flavin-containing monooxygenase (FMO) and P450 enzymes: selective catalysis by FMO3. Biochem Pharmacol. 1998;56(8):1005-12.

99. Wang Z, Klipfell E, Bennett BJ, Koeth R, Levison BS, Dugar B, et al. Gut flora metabolism of phosphatidylcholine promotes cardiovascular disease. Nature. 2011:472(7341):57-63.

100. Tang WH, Wang Z, Kennedy DJ, Wu Y, Buffa JA, Agatisa-Boyle B, et al. Gut Microbiota-Dependent Trimethylamine N-Oxide (TMAO) Pathway Contributes to Both Development of Renal Insufficiency and Mortality Risk in Chronic Kidney Disease. Circ Res. 2015;116(3):448-55.
101. Tang WH, Wang Z, Fan Y, Levison B, Hazen JE, Donahue LM, et al. Prognostic value of elevated levels of intestinal microbe-generated metabolite trimethylamine-N-oxide in patients with heart failure: refining the gut hypothesis. J Am Coll Cardiol. 2014;64(18):1908-14.

102. Tang WH, Wang Z, Shrestha K, Borowski AG, Wu Y, Troughton RW, et al. Intestinal microbiota-dependent phosphatidylcholine metabolites, diastolic dysfunction, and adverse clinical outcomes in chronic systolic heart failure. J Card Fail. 2015;21(2):91-6.

103. Tang WH, Wang Z, Levison BS, Koeth RA, Britt EB, Fu X, et al. Intestinal microbial metabolism of phosphatidylcholine and cardiovascular risk. $\mathrm{N}$ Engl J Med. 2013;368(17):1575-84.

104. Mendis S, Puska P, Norrving B, World Health Organization., World Heart Federation., World Stroke Organization. Global atlas on cardiovascular disease prevention and control. Geneva: World Health Organization in collaboration with the World Heart Federation and the World Stroke Organization; 2011. p. vi, 155.

105. Kruse JA, Carlson RW. Lactate metabolism. Crit Care Clin. 1987;3(4):725-46.

106. Phypers BPJ. Lactate physiology in health and disease. Continuing Education in Anaesthesia, Critical Care \& Pain. 2006;6(3):128-32.

107. Ramakrishna B, Graham SM, Phiri A, Mankhambo L, Duke T. Lactate as a predictor of mortality in Malawian children with WHO-defined pneumonia. Arch Dis Child. 2012;97(4):336-42.

108. Chen YX, Li CS. Lactate on emergency department arrival as a predictor of mortality and site-of-care in pneumonia patients: a cohort study. Thorax. 2015;70(5):404-10.

109. Kim WY, Lee YJ, Yeon Lim S, Ok Koh S, Choi Wl, Chan Kim S, et al. Clinical characteristics and prognosis of pneumonia and sepsis: multicenter study. Minerva Anestesiol. 2013;79(12):1356-65.

110. Rogers AJ, McGeachie M, Baron RM, Gazourian L, Haspel JA, Nakahira K, et al. Metabolomic derangements are associated with mortality in critically ill adult patients. PLoS One. 2014;9(1):e87538.

111. Belitz HD, Grosch W. Lehrbuch der Lebensmittelchemie. 3, u\0308berarbeitete Aufl. ed. Berlin. New York: Springer; 1987.

112. Foltran F, Gregori D, Caropreso A, Pagano E, Bruno A. Is blood glucose on admission a predictor of mortality in adult acute pneumonia? Clin Respir J. 2013;7(3):276-80.

113. McAlister FA, Majumdar SR, Blitz S, Rowe BH, Romney J, Marrie TJ. The relation between hyperglycemia and outcomes in 2,471 patients admitted to the hospital with community-acquired pneumonia. Diabetes Care. 2005;28(4):810-5.

114. Lepper PM, Ott S, Nuesch E, von Eynatten M, Schumann C, Pletz MW, et al. Serum glucose levels for predicting death in patients admitted to hospital for community acquired pneumonia: prospective cohort study. BMJ. 2012;344:e3397.

115. Trachootham D, Lu W, Ogasawara MA, Nilsa RD, Huang P. Redox regulation of cell survival. Antioxid Redox Signal. 2008;10(8):1343-74.

116. Forman HJ, Dickinson DA. Oxidative signaling and glutathione synthesis. Biofactors. 2003;17(1-4):1-12.

117. Biswas SK, Rahman I. Environmental toxicity, redox signaling and lung inflammation: the role of glutathione. Mol Aspects Med. 2009;30(1-2):60-76.

118. Rodas PC, Rooyackers O, Hebert C, Norberg A, Wernerman J. Glutamine and glutathione at ICU admission in relation to outcome. Clin Sci (Lond). 2012;122(12):591-7.

119. Huang CS, Chang LS, Anderson ME, Meister A. Catalytic and regulatory properties of the heavy subunit of rat kidney gamma-glutamylcysteine synthetase. J Biol Chem. 1993;268(26):19675-80.

120. Burgunder JM, Varriale A, Lauterburg BH. Effect of $\mathrm{N}$-acetylcysteine on plasma cysteine and glutathione following paracetamol administration. Eur J Clin Pharmacol. 1989;36(2):127-31.

121. Swart KM, van Schoor NM, Lips P. Vitamin B12, folic acid, and bone. Curr Osteoporos Rep. 2013;11(3):213-8.

122. Fratoni V, Brandi ML. B Vitamins, Homocysteine and Bone Health. Nutrients. 2015;7(4):2176-92.

123. Herzenberg LA, De Rosa SC, Dubs JG, Roederer M, Anderson MT, Ela SW, et al. Glutathione deficiency is associated with impaired survival in HIV disease. Proc Natl Acad Sci U S A. 1997;94(5):1967-72.

124. Xiu LL, Lee MS, Wahlqvist ML, Chen RC, Huang YC, Chen KJ, et al. Low and high homocysteine are associated with mortality independent of B group vitamins but interactive with cognitive status in a free-living elderly cohort. Nutr Res. 2012;32(12):928-39. 
125. Wong YY, Almeida OP, McCaul KA, Yeap BB, Hankey GJ, Flicker L. Homocysteine, frailty, and all-cause mortality in older men: the health in men study. J Gerontol A Biol Sci Med Sci. 2013;68(5):590-8.

126. Swart KM, van Schoor NM, Blom HJ, Smulders YM, Lips P. Homocysteine and the risk of nursing home admission and mortality in older persons. Eur J Clin Nutr. 2012;66(2):188-95.

127. Drewes YM, Poortvliet RK, Blom JW, de Ruijter W, Westendorp RG, Stott DJ, et al. Homocysteine levels and treatment effect in the PROspective Study of Pravastatin in the Elderly at Risk. J Am Geriatr Soc. 2014;62(2):213-21.

128. Waskiewicz A, Sygnowska E, Broda G. Homocysteine concentration and the risk of death in the adult Polish population. Kardiol Pol. 2012;70(9):897-902.

129. Naess $H$, Nyland $H$, Idicula T, Waje-Andreassen U. C-reactive protein and homocysteine predict long-term mortality in young ischemic stroke patients. J Stroke Cerebrovasc Dis. 2013;22(8):e435-40.

130. Vieira Ade L, Baptista A, Malho A, Pinho A, Silva AP, Bernardo I, et al. Homocysteine is a risk factor in predialysis patients when associated with malnutrition and inflammation. Int J Nephrol. 2010:2010:957645.

131. Holmsen H, Hindenes JO, Fukami M. Glycerophospholipid metabolism: back to the future. Thromb Res. 1992;67(3):313-23.

132. Sigruener A, Kleber ME, Heimerl S, Liebisch G, Schmitz G, Maerz W Glycerophospholipid and sphingolipid species and mortality: the Ludwigshafen Risk and Cardiovascular Health (LURIC) study. PLoS One. 2014;9(1):e85724

133. Drobnik W, Liebisch G, Audebert FX, Frohlich D, Gluck T, Vogel P, et al. Plasma ceramide and lysophosphatidylcholine inversely correlate with mortality in sepsis patients. J Lipid Res. 2003;44(4):754-61.

134. Bartke N, Hannun YA. Bioactive sphingolipids: metabolism and function. J Lipid Res. 2009:50(Suppl):S91-6.

135. Schlitt A, Blankenberg S, Yan D, von Gizycki H, Buerke M, Werdan K, et al. Further evaluation of plasma sphingomyelin levels as a risk factor for coronary artery disease. Nutr Metab. 2006;3:5.

136. Jiang XC, Paultre F, Pearson TA, Reed RG, Francis CK, Lin M, et al. Plasma sphingomyelin level as a risk factor for coronary artery disease. Arterioscler Thromb Vasc Biol. 2000;20(12):2614-8

137. Steiber A, Kerner J, Hoppel CL. Carnitine: a nutritional, biosynthetic, and functional perspective. Mol Aspects Med. 2004;25(5-6):455-73.

138. Kalim S, Clish CB, Wenger J, Elmariah S, Yeh RW, Deferio JJ, et al. A plasma long-chain acylcarnitine predicts cardiovascular mortality in incident dialysis patients. J Am Heart Assoc. 2013;2(6):e000542.

139. Christ-Crain M, Stolz D, Bingisser R, Muller C, Miedinger D, Huber PR, et al. Procalcitonin guidance of antibiotic therapy in community-acquired pneumonia: a randomized trial. Am J Respir Crit Care Med. 2006;174(1):84-93.

140. Van den Berghe G, de Zegher F, Bouillon R. Clinical review 95: Acute and prolonged critical illness as different neuroendocrine paradigms. J Clin Endocrinol Metab. 1998;83(6):1827-34

141. Brambilla DJ, Matsumoto AM, Araujo AB, McKinlay JB. The effect of diurnal variation on clinical measurement of serum testosterone and other sex hormone levels in men. J Clin Endocrinol Metab. 2009:94(3):907-13.

142. Pan WH, Hung YT, Shaw NS, Lin W, Lee SD, Chiu CF, et al. Elderly Nutrition and Health Survey in Taiwan (1999-2000): research design, methodology and content. Asia Pac J Clin Nutr. 2005;14(3):203-10.

143. Norman PE, Flicker L, Almeida OP, Hankey GJ, Hyde Z, Jamrozik K. Cohort Profile: The Health In Men Study (HIMS). Int J Epidemiol. 2009:38(1):48-52.

144. Tekin AS, Sengul C, Kilicaslan B, Ozveren O, Kozdag G. The value of serum homocysteine in predicting one-year survival in patients with severe systolic heart failure. Turk Kardiyol Dern Ars. 2012;40(8):699-705

\section{Submit your next manuscript to BioMed Central and take full advantage of:}

- Convenient online submission

- Thorough peer review

- No space constraints or color figure charges

- Immediate publication on acceptance

- Inclusion in PubMed, CAS, Scopus and Google Scholar

- Research which is freely available for redistribution 